An analysis of the vulnerability of poor communities in Yunnan province, China, to climate and socioeconomic changes

Su Yufang, Carly Biondi, Liu Song, Sabarnee Tuladhar, Nand Kisor Agrawal 


\section{An analysis of the vulnerability of poor communities in Yunnan province, China, to climate and socioeconomic changes}

Su Yufang, Carly Biondi, Liu Song, Sabarnee Tuladhar, Nand Kisor Agrawal 


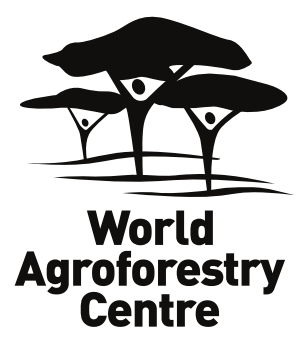

LIMITED CIRCULATION

Correct citation: Su Y, Biondi C, Song L, Tuladhar S, Agrawal N K. 2018. An analysis of the vulnerability of poor communities in Yunnan province, China, to climate and socioeconomic changes. Working Paper 286. Kunming, China: World Agroforestry Centre (ICRAF). DOI: http://dx.doi.org/10.5716/WP18021.PDF

Titles in the Working Paper series aim to disseminate interim results on agroforestry research and practices, and stimulate feedback from the scientific community. Other publication series from the World Agroforestry Centre include: Technical Manuals, Occasional Papers and the Trees for Change Series.

Published by the World Agroforestry Centre

Centre for Mountain Ecosystem Studies

\% Kunming Institute of Botany, Chinese Academy of Sciences

3/F North Research Building

Heilongtan, 650201 Kunming

Yunnan Province, P.R. China

Tel: $+86-871-65223014$

Fax: +86-871-6522 3377

Email: cmes@mail.kib.ac.cn

http://www.worldagroforestry.org/eca

(C) World Agroforestry Centre 2018

Working Paper No. 286

The views expressed in this publication are those of the author(s) and not necessarily those of the World Agroforestry Centre.

Articles appearing in this publication may be quoted or reproduced without charge, provided the source is acknowledged.

All images remain the sole property of their source and may not be used for any purpose without written permission of the source. 


\section{About the authors}

Su Yufang is an Associate Professor at Yunnan Academy of Social Sciences, and the Deputy Director of the Centre for Mountain Ecosystem Studies (CMES), a joint research centre of the Chinese Academy of Sciences and the World Agroforestry Centre, hosted by the Kunming Institute of Botany. She received her PhD from Mae Fah Luang University, Thailand, and has more than 20 years of research experience in the areas of resource governance, land tenure, rural development and local adaptation to climate change.

Carly Biondi is a project manager at the World Agroforestry Centre, East and Central Asia office. She holds a Master's degree in International Development from Concordia University, Irvine. Her research focuses on areas of rural development, local adaption to climate change, and participatory data collection.

Liu Song has 6 years of experience in management of multi-national programmes including but not limited to agriculture, freshwater conservation, policy and rural development. Besides that, he is an expert in web design and building, data analysis using $\mathrm{R}$, and presentation.

Sabarnee Tuladhar, a Nepali national, is a Research Associate at ICIMOD, where she works on the Livelihoods thematic area. Her work focuses on conducting socioeconomic and statistical data analysis for poverty and vulnerability mapping that provides information on population statistics. She holds a Master's degree in International Development and Environmental Analysis from Monash University, Australia.

Nand Kishor Agrawal works as a Programme Coordinator for the Himalayan Climate Change Adaptation Programme (HICAP) at the International Centre for Integrated Mountain Development (ICIMOD), Nepal. He has over 20 years of experience in management and execution of large-scale research and implementation programmes on natural resources, microfinance, livelihoods and development finance in Asia. His current activities focus on resilience-building local solutions, climate change adaptation and putting research into use, particularly for policy development in the countries of the Hindu Kush Himalayan region 


\begin{abstract}
In recent decades, due to rapid economic development and urbanization in China, there has been rapid and far-reaching socioeconomic change in mountain areas such as Yunnan Province. Yunnan has also historically been affected by climate-related natural disasters. The droughts of 2009-2012 are a recent example. However, comprehensive data is needed on the effect of such issues on local livelihoods with regard to their vulnerability to change and how corresponding behavioural shifts may mitigate or exacerbate the impact of these changes. A comprehensive research program at the International Centre for Integrated Mountain Development (ICIMOD) dubbed 'Himalayan Climate Change Adaptation Programme (HICAP)' has researched such topics in four countries within the Hindu Kush Himalayan region. For Yunnan province of China, the Centre for Mountain Ecosystem Studies (CMES), jointly with the HICAP team of ICIMOD, interviewed 1950 households, who comprised a representative sample of the population of five prefectures of Yunnan Province. This quantitative survey used the Poverty and Vulnerability Assessment (PVA): a research tool previously developed by the International Centre for Integrated Mountain Development (ICIMOD) (Gerlitz et al., 2014). The survey explored the vulnerability of the livelihoods of mountain communities to climatic and socioeconomic changes, as well as their adaptive capacity. The survey results are a perception-based response of the households that were interviewed and provide an overview of their impressions about issues including climate change, their vulnerabilities and finally their capacity to respond to change. The research demonstrated that people in the surveyed areas are already vulnerable to marginalization and climate change. Their dependency ratio and illiteracy rates are very high, and migrant workers are paid low wages. They also have little or no chance of participating in or influencing the formulation or implementation of government policies. Most households use hybrid seeds, and there has been a shift away from traditional staple crops to cash crops. The root causes of the vulnerability to changes in these communities, are not only environmental problems, but also include their social structure, institutional arrangements, lack of equity and community interactions.
\end{abstract}

Keywords: adaptive capacity, climate change, livelihoods, resilience 


\section{Acknowledgements}

This research is part of the Himalayan Climate Change Adaptation Programme (HICAP), which is implemented jointly by the International Centre for Integrated Mountain Development (ICIMOD), GRID-Arendal and the Centre for International Climate and Environmental Research - Oslo (CICERO), in collaboration with local partners. The initiative is funded by the governments of Norway and Sweden. It aims to contribute to enhancing the resilience of mountain communities, particularly among women, through increasing understanding of these communities' vulnerabilities, opportunities and potential for adaptation to change. Additional funding was provided by the 'gender cross-cutting' component of the CGIAR- Global Research Program on 'Forests, Trees, and Agroforests' (FTA). We thank Fiona Worthy for providing comments, and Fiona Worthy and Andrew Stevenson for editing and layout. Special thanks go to the kindhearted local people throughout the areas who participated in our survey. We are grateful to Ms. Zhang Qian and Mr. Ren Jian who led the field survey and trained the enumerators/students who patiently conducted individual interviews. The input of all these people was invaluable to the survey. 


\section{List of Abbreviations}

\begin{tabular}{ll} 
ALDI & Agricultural Livelihood Diversification index \\
CDI & Crop Diversity Index \\
CICERO & Centre for International Climate and Environmental Research - Oslo \\
CMES & Centre for Mountain Ecosystem Studies \\
FTA & Forests, Trees, Agroforests \\
GRP & Gross Regional Product \\
HH & Household \\
HICAP & Himalayan Climate Change Adaptation Programme \\
HKH & Hindu Kush Himalaya \\
ICIMOD & International Centre for Integrated Mountain Development \\
IPCC & Intergovernmental Panel on Climate Change \\
LVI & Livelihood Vulnerability Index \\
NMIC & National Meteorological Information Centre \\
NTFPs & Non-timber Forest Products \\
PVA & Poverty and Vulnerability Analysis \\
RCP & Representative Concentration Pathways \\
SES & Socio-economic Status \\
UNICEF & United Nations Children's Fund \\
USD & United States Dollar \\
& \\
\hline
\end{tabular}




\section{Table of Contents}

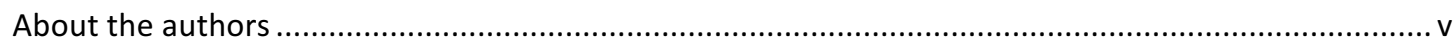

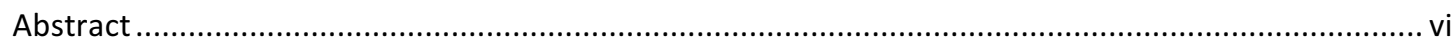

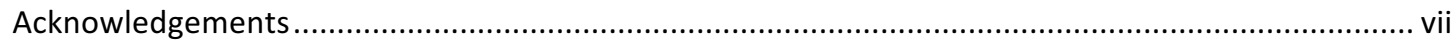

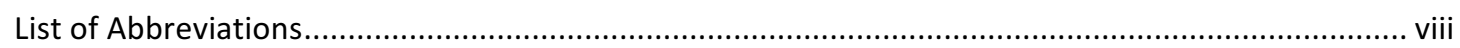

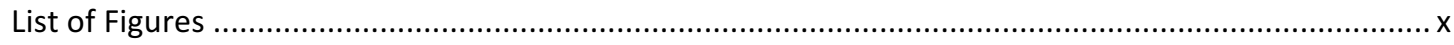

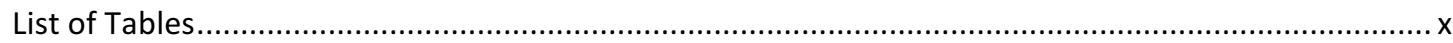

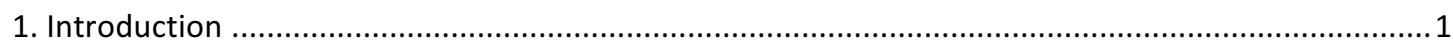

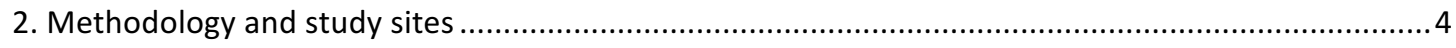

2.1 Poverty and vulnerability assessment ............................................................................ 4

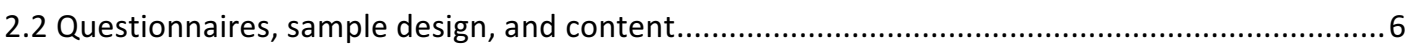

2.3 Background details regarding Yunnan Province that relate to the LVI comparison .................... 7

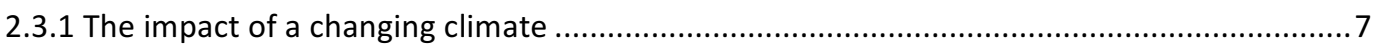

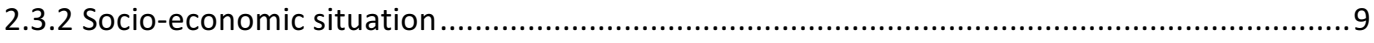

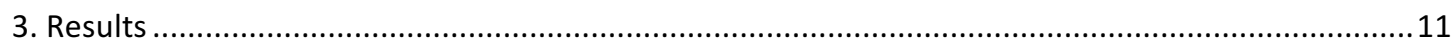

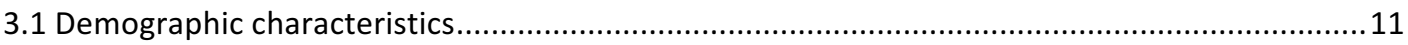

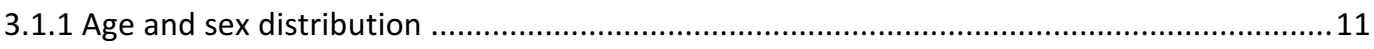

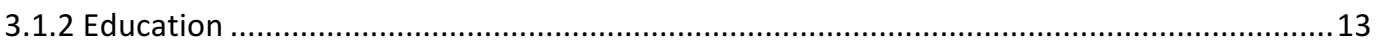

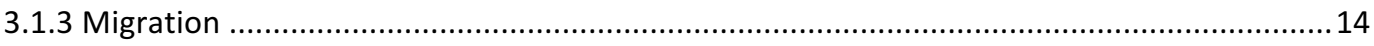

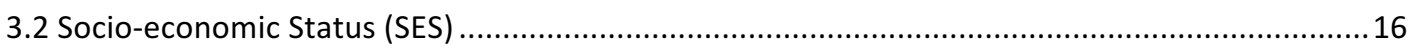

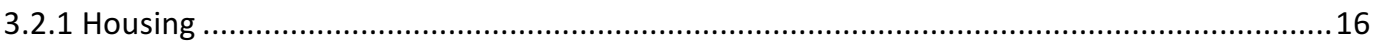

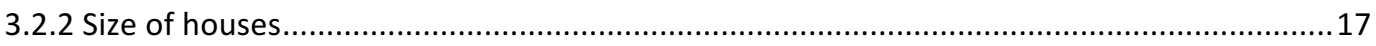

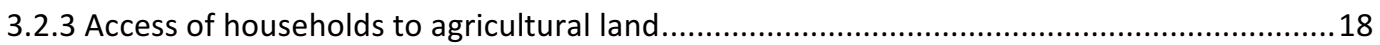

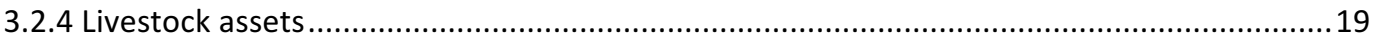

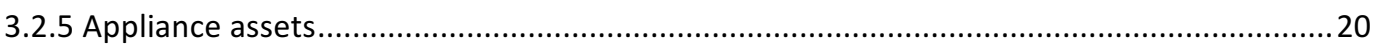

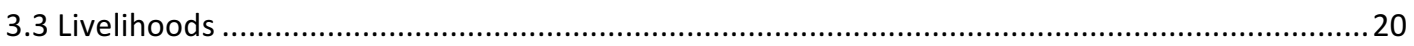

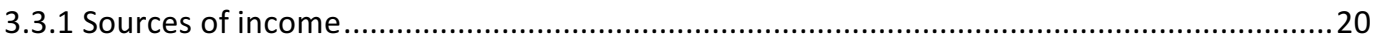

3.3.2 Household patterns of consumption and expenditure ....................................................2 21

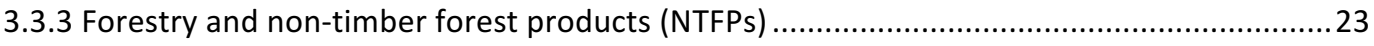

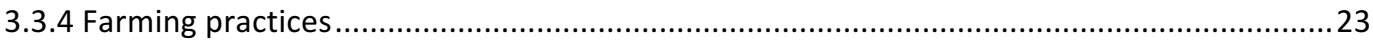

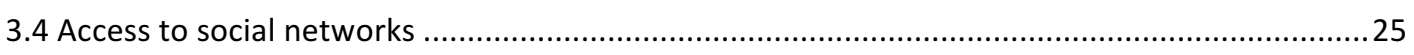

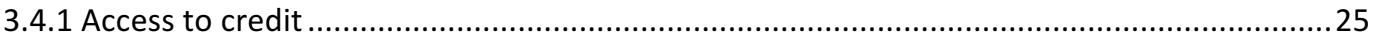

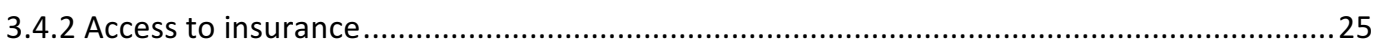

3.4.3 Household involvement in community organizations ....................................................26

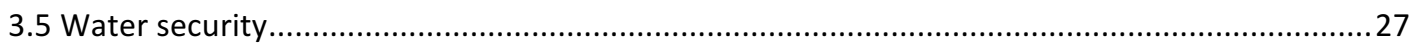

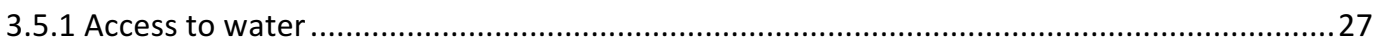

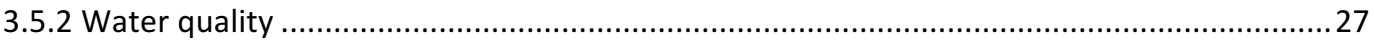

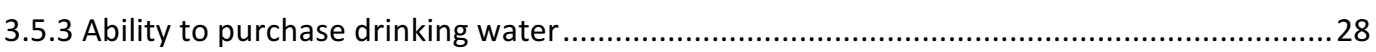

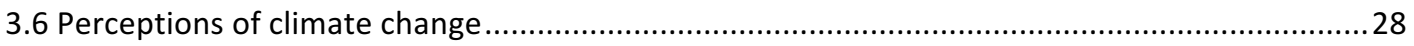




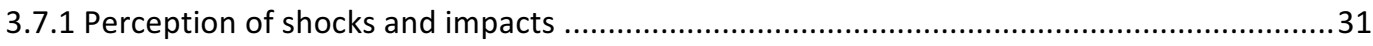

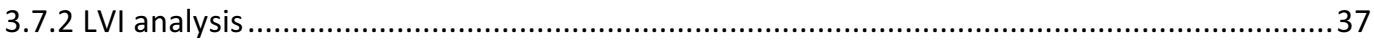

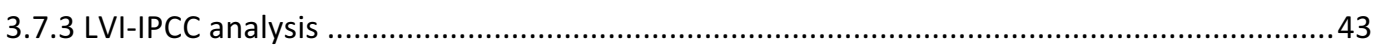

4.1 Overall vulnerability to climate change and variations across the surveyed areas ....................45

4.2 Food and social networks: the strongest indicators of vulnerability ........................................46

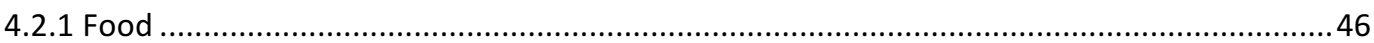

4.3 Agricultural vulnerability to climate change and communities' adaptation strategies ..............47

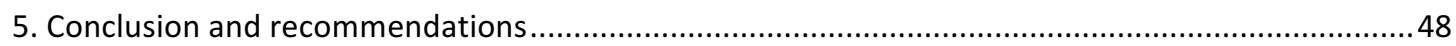

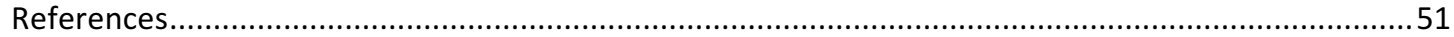

\section{List of Figures}

Figure 1: Possible shifts of bioclimatic zones in Yunnan Province according to projected greenhouse gas emission Representative Concentration Pathways (Zomer, 2015) ............................................... 8

Figure 2: Map of study sites in Yunnan Province............................................................................. 11

Figure 3: Educational profile of surveyed household heads.......................................................... 14

Figure 4: Total remittances per person per year from employment migration (USD) .........................16

Figure 5: Total remittances per year from employment migration (USD) ........................................... 16

Figure 6: Materials for exterior wall in five prefectures.........................................................................16

Figure 7: Materials for the main roofs of the houses in five prefectures................................................17

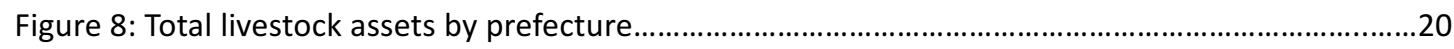

Figure 9: Percentage of total respondents that are members of community organizations ..................26

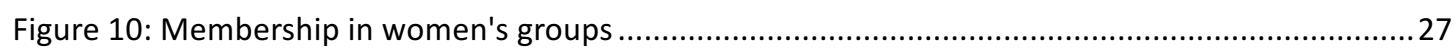

Figure 11: Percentage of total respondents that perceived climate change over the last 10 years.......30

Figure 12: The value of LVI of surveyed prefectures: a graphical representation............................... 43

Figure 13: The value of LVI-IPCC of surveyed prefectures .............................................................4 44

\section{List of Tables}

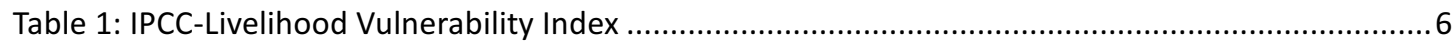

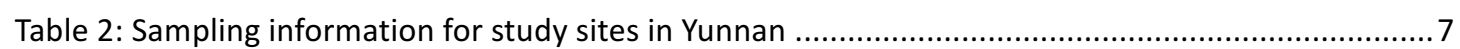

Table 3: Age structure of Yunnan Province in the Sixth National Census ............................................9

Table 4: PVA based profile of households' members in five prefectures in Yunnan..............................13

Table 5: Education profile for household heads in this survey .......................................................... 14

Table 6: PVA index of migration of household members from five prefectures in Yunnan .................... 15

Table 7: Earnings by gender in each prefecture (USD/month) ........................................................ 15

Table 8: Average number of rooms per household and cost per house per month to rent .................. 18

Table 9: Average plot size per household in each of five prefectures......................................................18

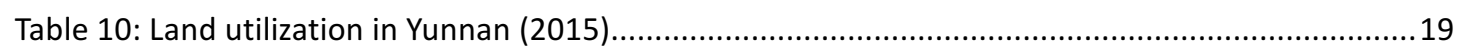

Table 11: The number of motor vehicles in surveyed areas ................................................................20

Table 12: Main sources of income for surveyed prefectures............................................................21

Table 13: Total value of food, cigarette and alcohol purchases per month per household ....................21 
Table 14: Total monthly expenditure on non-food items per households in surveyed prefectures.......22

Table 15: Total monthly expenditure per household in surveyed prefectures ....................................22

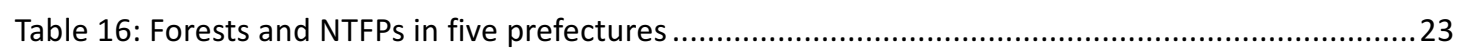

Table 17: Number of staple crops planted across five prefectures...........................................................24

Table 18: Number of cash crops planted across five prefectures .....................................................24

Table 19: Debt status of households in surveyed prefectures.............................................................25

Table 20: Percent of surveyed of households covered by insurance....................................................26

Table 21: Percentage of households needing to collect water from other areas, for five prefectures

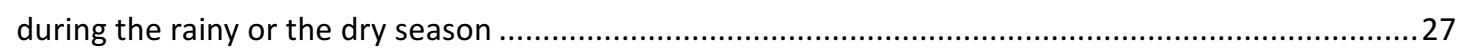

Table 22: Percentage of households that treat their drinking water....................................................28

Table 23: Percentage of households who had observed climate change .............................................29

Table 24: Severity of shocks and damage in Lincang, by gender of the head of each household............33

Table 25: Severity of shocks and damage in Baoshan, according to gender of the head of household.33

Table 26: Severity of shocks and damage in Dali by gender of head of household...............................34

Table 27: Severity of shocks and associated damage in Diqing by gender of head of household ...........35

Table 28: Severity of shocks and associated damage in Nujiang by gender of head of household.........35

Table 29: Whether respondents sought help from fellow members of their community......................36

Table 30: Whether respondents sought help from community organizations .......................................36

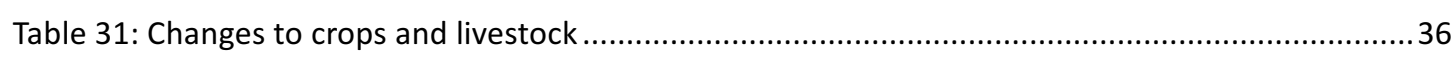

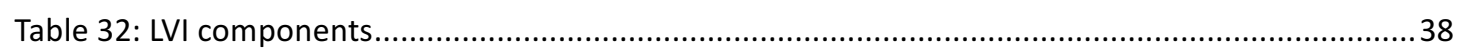

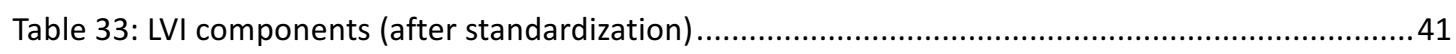

Table 34: The value of LVI in the prefectures in this survey ...............................................................42 


\section{Introduction}

The main focus of this report is an analysis of communities' vulnerability to climate change in Yunnan province, China. For the purpose of this report, we define vulnerability as 'the propensity of a group of people or sector to suffer harm' (Nadin, Opitz-Stapleton \& Xu, 2016) as a result of the interaction of hazards with socio-economic, political and environmental circumstances at the international, national and local level. Vulnerability is deeply influenced by relationships between the dynamics of environmental and development factors within China. Extreme climate events such as droughts, floods, landslides and earthquakes are frequent occurrences in China. Development factors influencing vulnerability, such as rural-urban migration, uneven industrial development, population growth, and ever-increasing resource extraction, have rapidly changed the nation's landscape - environmentally, politically, economically and socially - so that new connections between components of sensitivity have altered communities' exposure and responses to climate change (Nadin, Opitz-Stapleton \& Xu, 2016). This developmental context coupled with intensity and frequency of extreme weather events have increased the exposure to risk of some communities.

This report is part of a series of publications produced from the Poverty and Vulnerability Assessment (PVA) research carried out under the Himalayan Climate Change Adaptation Programme (HICAP) at ICIMOD in the Hindu Kush Himalayan region (HKH) which extends over eight countries, Afghanistan, Bangladesh, Bhutan, China, India, Myanmar, Nepal and Pakistan. The region hosts ten large river systems, which sustain a population of around 240 million people in a region of over 3 million $\mathrm{km}^{2}$. Additionally, these river basins provide water to 1.9 billion people: a fifth of the world's population (ICIMOD, 2016). The HKH region contains heterogeneous environments and microclimates. This area is culturally, biologically and environmentally diverse. Indigenous communities are mostly agrarian and heavily reliant on natural resources. Yunnan province lies within the boundaries of the Hindu Kush Himalayan region. Many of the characteristics of mountain communities, such as poor access to health care, few resources, and limited access to markets, deeply affect Yunnan's communities' vulnerability to climate change.

Climate change can be divided into both slow- and fast-onset events (Nadin, Opitz-Stapleton \& Xu, 2016). Slow-onset climate change has been witnessed through the global rise in temperatures and sea levels over the last 50 years. Fast-onset climate change refers to extreme weather events, including hurricanes and heat waves (Nadin, Opitz-Stapleton \& Xu, 2016). Both these categories of climate change are affecting China. Overall, the country has experienced an average temperature increase of $1.38^{\circ} \mathrm{C}$ between 1951 and 2009 (Compilation Committee of the Second National Assessment Report on Climate Change, 2011). However, this general trend has had more regional consequences, especially in the northern regions and the Tibetan Plateau, where winter temperatures have become milder, and in the Southwest of China where delays in seasonal changes have been detected (Nadin, Opitz-Stapleton \& Xu, 2016). Nationwide, there has been greater variability in precipitation. The main regional changes have been increasing incidences of flooding in the south but worsening droughts in the north. In addition, the 
frequency of both cold snaps and heat waves have increased throughout the country. As a result of these measurable shifts, four areas with intense vulnerability to climate change have been identified: the arid to semi-arid northwest, the Tibet-Qinghai Plateau, the karst uplands of southwest China and the urban coastal centres (Nadin, Opitz-Stapleton \& Xu, 2016). This report is primarily concerned with identifying how hazards (arising from either slow- or fast-onset events), in combination with pre-existing vulnerabilities can develop into disasters in the southwest China. This is often referred to as a disaster-chain analysis. Through this type of analysis, secondary and tertiary events can be identified through causal links. Secondary and tertiary events are occurrences that are trigged by exposure to an initial hazard, and then increase the overall damage due to the disaster. The identification of causal links between the initial hazard and the secondary and tertiary events determines disaster risk, which is calculated from the frequency and intensity of a hazard and hazard-affected entities (any system that may be negatively affected as a result of the hazard) (Nadin, Opitz-Stapleton \& Xu, 2016). Often, secondary and tertiary events (primarily concerning hazard-affected entities) are more dangerous than the initial hazard. The following anecdotal evidence will help illustrate the concept of disaster-chains.

"Five villagers have been killed and 11 others are missing after rain-triggered flooding hit a county in southwest China's Yunnan Province. Fifteen people were injured in the disaster in Huaping County, according to an updated casualty list provided by the county government on Wednesday afternoon. Downpours swept Huaping from Tuesday night to the early hours of Wednesday, with precipitation of $282.4 \mathrm{~mm}$. The storm caused the local Liyu River to break its banks, inundating several residential communities and causing record flooding in one community. The houses of 72 rural families collapsed and 244 others were damaged" [KUNMING, Sept. 16, 2015 (Xinhua)] ${ }^{1}$.

"A total of 45 people have died and two others are missing due to floods triggered by downpours in southwest China's Yunnan Province, local authorities said on Monday. From May 1 when the province entered the flood season to Aug. 20, 1.63 million people had been affected by flooding and 26,500 people were forced to relocate, according to the provincial flood control and drought relief headquarters" [KUNMING, Aug. 26, 2013 (Xinhua)]².

If the hazard-affected entities such as the river embankment had been fortified appropriately (e.g. by sandbags) or the nearby town had not had pre-existing soil erosion thus creating conditions susceptible to landslides, perhaps exposure to heavy rains would not have caused such a disaster. Climate variability and changes had a major impact on all aspects of livelihoods. These have affected local microclimates and traditional livelihoods. In many cases, climate change is outpacing autonomous adaptation and is overwhelming the ability of the poor to adapt to change. Under projected scenarios of climate change, previously sustainable livelihoods may become unsustainable due to biophysical and social drivers of vulnerability. In order to improve people's resilience, government climate change policies should incorporate local stakeholders to ensure that efforts to bolster adaptive capacity are compatible with local microclimates.

Farming communities in mountainous areas like Yunnan are often heterogeneous and vulnerability differs between the various social segments of these communities. Social hierarchy

\footnotetext{
${ }^{1}$ http://news.xinhuanet.com/english/2015-09/16/c_134630392.htm, accessed on May 9, 2017.

2 http://news.xinhuanet.com/english/china/2013-08/26/c_132664109.htm, accessed on May 9, 2017. 
systems, geographic locations such as being in the upstream or downstream of a flooding event, and access to available resources are key factors that determine levels of marginalization within mountain communities. Therefore, any adaptation planning at a community level that aims to leverage existing capacities for adaptation must take into account these differences in vulnerability. This applies especially to climate change adaptation programs which require an assessment of local vulnerabilities, especially of the vulnerability of the most marginalized and poorest communities, in order to bridge the gap between government policy and local practices and needs (Maharjan et al., 2017).

The field of 'climate vulnerability assessment' has emerged to address the need to quantify how communities will adapt to changing environmental conditions. Various researchers have tried to bridge the gap between the social, natural and physical sciences, and contributed new methodologies to handle this challenge. Many rely on the IPCC working definition of vulnerability as a function of exposure, sensitivity and adaptive capacity (IPCC, 2001b: 995; IPCC 2007:883). According to this definition, exposure is the degree to which a system is exposed to significant climate variations such as drought or change in temperature and precipitation.

Sensitivity is 'the degree to which a system is modified or affected by perturbations' (Adger, 2006). In the context of climate, 'sensitivity is the degree to which a system is affected, either adversely or beneficially, by a hazard. Sensitivity encompasses all the elements of climate change, including mean climate characteristics, climate variability, and the frequency and magnitude of extreme events. The effect may be direct (e.g., a change in crop yield in response to a change in the mean, range, or variability of temperature) or indirect (e.g., damage caused by an increase in the frequency of coastal flooding due to sea-level rise') (IPCC, 2001c: 6).

Adaptive capacity is "the ability or potential of a system to respond successfully to climate variability and change, and includes adjustments in both behaviour and in resources and technologies' (IPCC, 2007). In this study, adaptation will be considered as a process of adjusting to climatic changes that influence human wellbeing and survival, which occur at different levels, with different actors, at different levels of consciousness, purpose and timing with the purpose of reducing vulnerability. An integral part of adaption is innovation, 'which refers to the development of new strategies or technologies, or the revival of old ones in response to new conditions is an important aspect of adaptation, particularly under uncertain future climate conditions' (IPCC, 2007). In many cases, innovative technological solutions can increase adaptive capacity to climate change and take advantage of some of the opportunities that result from climate change, such as longer growing seasons and the consideration of new crops. Without well-developed adaptive capacity, communities will not reap the full benefit of the opportunities that climate change might bring to an area. Adaptive capacity is often deeply affected by social factors such as human capital, local customs and government structures (IPCC, 2007). In rural mountain communities, specific technological solutions that are needed for mountain areas are less likely to be available.

By identifying the biophysical and human behavioural drivers of change in this region, better policies and development practices can be developed to mitigate vulnerability (Fazey et al., 2010). Vulnerability studies have been conducted in rural areas around the world; however, the Hindu Kush Himalayan region is a very special zone in which $\mathbf{2 4 0}$ million people are living in mountains, 
and 1.9 billion in downstream areas (ICIMOD, 2016). These areas require very location-specific assessments as the findings from one side of the mountains cannot be generalized for the other side of the mountains, despite their close proximity. The consequences of climate change in the Hindu Kush Himalayan region affects 8 countries and 10 major river basins and therefore is critical to understanding how Asian countries can adapt to climate change (ICIMOD, 2016). Vulnerability assessments are crucial for policy design that targets climate change. These assessments enable policymakers or researchers to formulate clear and effective responses.

However, it is important to be aware that the survey is based on responses given by the participants according to their subjective perceptions. While such responses may differ between individuals, they provide a good overview at the aggregate level. Therefore, specific responses presented in the text should be contextualized and viewed accordingly.

\section{Methodology and study sites}

\subsection{Poverty and vulnerability assessment}

Poverty and Vulnerability Assessment (PVA) has been designed as a survey tool by the Himalayan Climate Change Adaptation Programme (HICAP) to assess vulnerability and adaptive strategies of households in the mountain region in the context of climate change in order to understand existing vulnerabilities, opportunities and potential for adaptation specific to the Hindu Kush Himalayan region. PVA uses the Livelihood Vulnerability Index (LVI), which was constructed by Hahn et al. (2009) by combining techniques and ideas from a variety of climate vulnerability assessments and LVI-IPCC, which aggregates the components of livelihood into the IPCC's three contributing factors to vulnerability-exposure, sensitivity, and adaptive capacity - to represent the IPCC definition of vulnerability, each of which is represented by a number of indicators, including social demographic, livelihoods, health, social networks, food, water, natural disaster and climate variability. The indicators were developed based on a literature review and expert consultation. Several sub-indicators were modified from Hahn's original analysis to adjust LVI to contextual factors in Yunnan Province (See Table 1).

The LVI uses a weighted-average approach (Hahn et al. 2009), where each sub-component contributes equally to the overall index even though each major component comprises a variable number of sub-components. Because each of the sub-components was measured on a different scale, they were standardized as an index.

$$
\text { index }_{\text {sdij }}=\frac{\mathrm{s}_{d}-\mathrm{S}_{\text {jmin }}}{\mathrm{s}_{\text {jmax }}-\mathrm{S}_{\text {jmin }}}
$$

Where, $S_{d}$ is the sub-component of the studied group $d$, and $S j_{\min }$ and $S j_{\max }$ are the minimum and maximum values, respectively, for each sub-component in all studied groups. These minimum and maximum values were used to transform this indicator into a standardized index. The maximum and minimum values were also transformed following this logic, and the equation above was applied to standardize these sub-elements. The mean of the standardized elements of the sub-components was taken in order to calculate the value of each major component using formula 2.

$$
\mathrm{M}_{d}=\sum_{\mathrm{i}=1}^{\mathrm{n}} \operatorname{index}_{s d i / n \ldots \ldots \ldots \ldots \ldots . . . .}(2)
$$

Where, $M_{d}=$ one of the seven major components of each studied group $d$ [Socio-Demographic 
Profile (SDP), Livelihood (L), Social Networks (SN), Health (H), Food (F), Water (W), or Natural Disasters and Climate Variability (NDC)]. The index ${ }_{\text {sdi }}$ represents the sub-components, indexed by $M_{d}$, that make up each major component, and $n$ is the number of sub-components in each major component. The Livelihood Vulnerability Index for each studied group $\left(L V I_{d}\right)$, scaled from 0 (least vulnerable) to 1 (highly vulnerable), was obtained by weighted average values of each of the seven major components as follows:

$$
\begin{aligned}
& \mathrm{LVI}_{d}=\sum_{\mathrm{i}=1}^{7} w \mathrm{MiM} d i / \sum_{\mathrm{i}=1}^{7} w \mathrm{M} i \text { or } \\
& \mathrm{LVI}_{d}=\frac{\mathrm{W}_{\mathrm{SDP}} \mathrm{SDP}_{\mathrm{d}}+\mathrm{W}_{\mathrm{LS}} \mathrm{L}_{\mathrm{Sd}}+\mathrm{W}_{\mathrm{SN}} \mathrm{SNA}_{\mathrm{d}}+\mathrm{W}_{\mathrm{H}} \mathrm{H}_{\mathrm{d}}+\mathrm{F}_{\mathrm{F}} \mathrm{Wd}+\mathrm{W}_{\mathrm{W}} \mathrm{W}_{\mathrm{d}}+\mathrm{W}_{\mathrm{NDC}} \mathrm{NDC}_{\mathrm{d}}}{\mathrm{W}_{\mathrm{SDP}}+\mathrm{wLS}+\mathrm{wSN}+\mathrm{wH}+\mathrm{F}_{\mathrm{F}+\mathrm{wW}+\mathrm{wNDC}}} \ldots
\end{aligned}
$$

\section{IPCC framework for calculating LVI}

For LVI-IPCC, the seven major components of LVI were divided into three categories, namely exposure, adaptive capacity and sensitivity. In this approach, each major component comprises several sub-components or indicators, as in the standard LVI. Similarly, Equations 1-3 were applied to calculate the LVI-IPCC. Instead of one weighted average, as in the standard LVI approach, we used three weighted averages of the major sub-elements, computed according to the three contributing factors. An index of exposure (Exp) calculated from natural disaster and climatic variability (Equation 4), sensitivity (Sen) containing health, food and water (Equation 5), and adaptive capacity (Adp. Cap) containing the socio-demographic profile, livelihood strategies, and social network have been calculated as follows:

$$
\operatorname{Exp}_{d}=\frac{W_{e 1} N D+W_{e 2} C V}{W_{e 1}+W_{e 2}}
$$

$W_{e 1}$ and $W_{e 2}$ are the weight for natural disasters and climatic variability, respectively, and equal to the number of sub-components. We assumed that the higher the rate of change of the climate variables and the higher the frequency of natural disasters, the higher will be the exposure of HHs to climate change and extreme weather events.

$$
\operatorname{Sen}_{d}=\frac{W_{s 1} H+W_{s 2} F+W_{s 3} W}{W_{s 1}+W_{s 2}+W_{s 3}}
$$

Where, $W_{s 1}, W_{s 2}$ and $W_{s 3}$ are the weights for major components health, food and water, respectively.

$$
A d p \cdot \operatorname{cap}_{d}=\frac{W_{a 1} S D P+W_{a 2} L S+W_{a 3} S N}{W_{a 1}+W_{a 2}+W_{a 3}}
$$

Where, $W_{a 1}, W_{a 2}$, and $W_{a 3}$ are the weights for the socio-demographic profile, livelihood strategies and social networks respectively.

The three contributing factors were combined using Equation (8) to calculate the LVI-IPCC.

$$
L V I-I P C C_{g}=\left(\operatorname{Exp}_{g}-\text { Adp.cap }\right) * \operatorname{Sen}_{g}
$$

Where, $L V I-I P C C_{g}$ is the LVI for the studied group, using the IPCC vulnerability framework; Exp. is the exposure score; Adp.cap.is the adaptive capacity score (weighted average of the socio-demographic, livelihood strategies, and social networks major components); and Sen. is the sensitivity score (weighted average of the heath, food, and water major components). 
Table 1: IPCC-Livelihood Vulnerability Index

\begin{tabular}{|c|c|c|}
\hline $\begin{array}{c}\text { IPCC- } \\
\text { Vulnerability }\end{array}$ & Major components & Sub-components \\
\hline \multirow[t]{3}{*}{ Adaptive Capacity } & Social-demographic & $\begin{array}{l}\text { Dependency Ratio } \\
\% \text { of female-headed households } \\
\% \text { of household heads who had never attended school } \\
\text { Average age of Household head }\end{array}$ \\
\hline & Livelihoods & $\begin{array}{l}\% \text { of households with family members not working in } \\
\text { their own community } \\
\% \text { of households entirely dependent on agriculture as } \\
\text { income source } \\
\text { Average Agricultural Livelihood Diversification Index }\end{array}$ \\
\hline & Social networks & $\begin{array}{l}\text { Index of potential channels for seeking help } \\
\text { Influence on local community's decision making } \\
\text { Access to borrowing money } \\
\% \text { of households in different organizations }\end{array}$ \\
\hline \multirow[t]{3}{*}{ Sensitivity } & Health & $\begin{array}{l}\% \text { of households' health seriously affected by natural } \\
\text { disasters } \\
\text { Affordability of treatment for serious illness or injury } \\
\text { Frequency of serious illness }\end{array}$ \\
\hline & Food & $\begin{array}{l}\text { Crop Diversity Index } \\
\text { Food Purchasing Index } \\
\% \text { of households that do not save seeds }\end{array}$ \\
\hline & Water & $\begin{array}{l}\text { Affordability of frequent water purchases } \\
\text { Drinking water source } \\
\text { Drinking water treatment } \\
\text { Water Quality }\end{array}$ \\
\hline Exposure & $\begin{array}{c}\text { Natural disasters and } \\
\text { climate variability }\end{array}$ & $\begin{array}{l}\text { Probability of landslides/mudslides } \\
\text { Mean standard deviation of monthly average of } \\
\text { average maximum daily temperature (years: } 1980- \\
2010) \\
\text { Mean standard deviation of monthly average of } \\
\text { average minimum daily temperature (years: } 1980- \\
2010) \\
\text { Mean standard deviation of monthly average } \\
\text { precipitation (years: } 1980-2010 \text { ) }\end{array}$ \\
\hline
\end{tabular}

\subsection{Questionnaires, sample design, and content}

The standard PVA questionnaire developed by ICIMOD for the entire Hindu Kush Himalayas was modified for the Yunnan context. Based on the needs of PVA, the survey contained a 17-page questionnaire, which attempted to capture a range of information on accessibility, vulnerability and adaptive capacity. This study defines the head of a household as the person who manages outside affairs for the household. Translation of the PVA questionnaires, selection of enumerators, and finalization of field sites within the prefectures were completed in June 2012. Instruction of the PVA trainers and enumerators took place in Kunming, and the field-testing was conducted 
and completed in July 2012. Field site selection and questionnaire testing was jointly conducted by ICIMOD and CMES staff in Dali Prefecture for 5 days in August 2012. During the first round of fieldwork we checked the results of the questionnaires at the end of each working day. Based on these initial results, we conducted follow-up household visits (from mid-August to mid-October 2012). The interdisciplinary survey team was comprised of 2 researchers and 15 enumerators from the World Agroforestry Centre (ICRAF), the Kunming Institute of Botany (KIB), Yunnan Academy of Social Sciences, Yunnan Agriculture University, and Yunnan University of Nationalities.

All statistics were calculated using R ( $R$ Core Team, 2014) from our demographic data in the study areas. In total, 1950 households were surveyed within 5 prefectures: Baoshan, Dali, Lincang, Diqing, and Nujiang (on average covering 390 households per prefecture). The findings of the PVA would be useful at the prefecture level. Prefectures were deliberately chosen within the project area. However, within each prefecture, counties were randomly selected. Within each county, villages were randomly selected. In total, the PVA survey was conducted in 65 randomly selected villages within 13 counties, which all belong to 5 of the prefectures of Yunnan.

Table 2: Sampling information for study sites in Yunnan

\begin{tabular}{|l|l|l|l|l|l|l|l|}
\hline Prefecture & \multicolumn{4}{|c|}{ Lincang } & \multicolumn{4}{c|}{ Baoshan } \\
\hline County & Zhenkang & Fengqing & Yongde & Longyang & Shidian & Changning \\
\hline No. of villages & 4 & 5 & 4 & 5 & 4 & 4 \\
\hline Prefecture & \multicolumn{3}{|c|}{ Dali } & \multicolumn{3}{c|}{ Diqing } & \multicolumn{3}{c|}{ Nujiang } \\
\hline County & Jianchuang & Eryuan & Yongping & Deqin & Weixi & Lushui & Lanping \\
\hline No. of Villages & 5 & 4 & 4 & 6 & 7 & 5 & 5 \\
\hline
\end{tabular}

\subsection{Background details regarding Yunnan Province that relate to the LVI comparison}

\subsubsection{The impact of a changing climate}

Yunnan has two distinct seasons: the rainy season and the dry season. Rainfall in Yunnan is abundant, but is unevenly distributed throughout the year (Huang, Chen, Zhu, Wang \& He, 2015). Most places in Yunnan province have annual rainfall of above $1100 \mathrm{~mm}$, but $85 \%$ of total rainfall is between May and October. These months are considered the rainy season. The dry season is from April to November ${ }^{3}$.

Climate change has seriously affected households in Yunnan (Zomer, 2015), particularly in minority areas where additional marginalization increases overall vulnerability. The annual mean temperature in Southwest China had increased by $0.12^{\circ} \mathrm{C}$ per decade during 1961-2010 (Ma, Liu, Zhang, Chen \& Yang, 2013), and the actual annual precipitation in Yunnan during the 1961-2012 decreased about $1 \mathrm{~mm}$ per year (China National Climate Center). Ma, Liu and Ying (2013) examined the observed and future impacts of climate change on agriculture, energy, natural resources and human health in Yunnan Province and southwest China based on data spanning

\footnotetext{
${ }^{3}$ http://mt.sohu.com/20160503/n447439198.shtml, accessed on May 9, 2017.
} 
from 1961 to 2010. They concluded that agriculture in Southwest China has been hugely affected by climate change (Ma, Liu \& Yang, 2013; Zomer, 2015). Increased temperatures and decreased precipitation have been experienced in Yunnan during the past 50 years (Chen \& Xie, 2008; Liu et al., 2010; Duan \& Tao, 2012). Both the potential productivity of crops and actual production decreased because although the growing season begins earlier in the year, the growing season has become shorter (Ma, Liu \& Yang, 2013). Since the 1980s, climate change has also affected the hours of sunshine per day, which has had an impact on crop productivity. Increasing temperatures have also increased the populations of crop pests and the prevalence of disease, and forest fires (Ma, Liu \& Yang, 2013). The data recorded below are in accordance with previous studies which indicate that the greatest seasonal variation has been in the summer and winter. Climate models predict that crops will need to be planted at higher altitudes to enable multiple cropping. Even then, winter wheat production is predicted to decline by $30-60 \%$ by 2070 (Ma, Liu \& Yang, 2013).

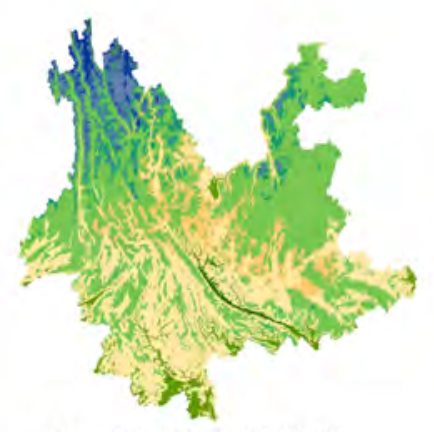

Year $1960-2000$ - World Clim

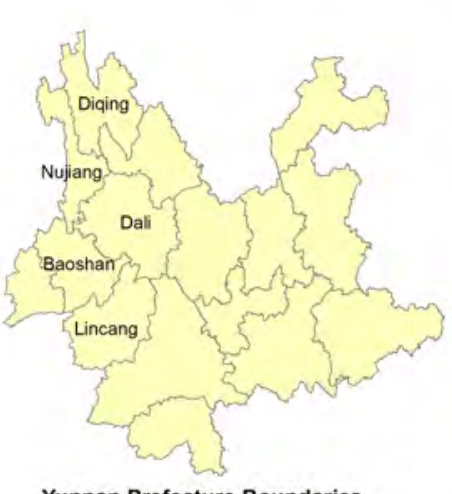

Yunnan Prefecture Boundaries
Yunnan Province - Bioclimatic Zones
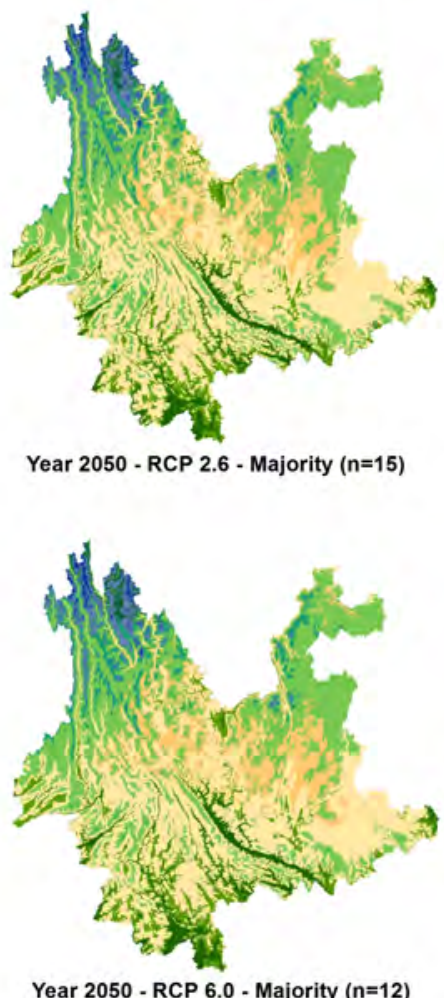

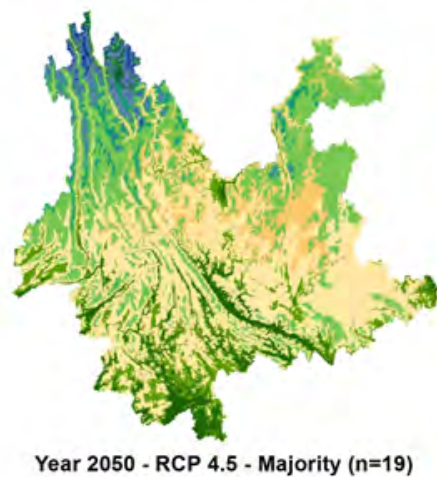

Bioclimatic Zones

Year 2050 - RCP 4.5 - Majority (n=19)

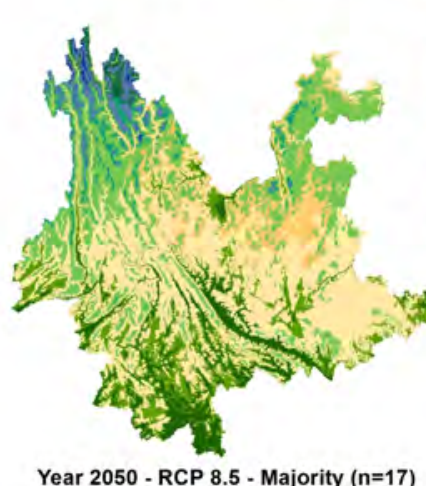
Extremely cold and mesic
Cold and mesic Cool temperate and mesic Cool temperate and moist Warm temperate and mesic Warm temperate and xeric Hot and mesic Extremely hot and mesic Extremely hot and moist

Figure 1: Possible shifts of bioclimatic zones in Yunnan Province according to projected greenhouse gas emission Representative Concentration Pathways (Zomer, 2015)

Climate change has been linked to health issues in rural communities. Increasing temperature and sporadic changes in precipitation have increased eutrophication and fog (Ma, Liu \& Yang, 2013). In 2009, 62.7\% of Yunnan was affected by eupatorium, with $10 \mathrm{~km}$ per year extension northward (Xiao, Zhou \& Quan, 2009). Eutrophication is an enrichment of a water body with extra nutrients (the result of too many plants growing on the surface of a river, lake etc., often 
because chemicals that are used for crops have been carried into the water by rain. Eutrophication of freshwater in the lakes of the Yunnan-Guizhou Plateau directly affected the quality of drinking water for populations in this area (Ma, Liu \& Yang, 2013). The increased incidence of days of fog per year has also increased respiratory infection rates (Ma, Liu \& Yang, 2013). Increasing temperatures have made higher altitudes and more northwest regions of Yunnan susceptible to malaria epidemics (Ma, Liu \& Yang, 2013), where historically this had not been a problem. Rural communities that lack resources and basic goods and services, like healthcare and clean water, cannot mitigate these consequences, and adapt to climate change unless they are provided with new knowledge and resources.

\subsubsection{Socio-economic situation}

According to the data from a random sample of 1\% people of Yunnan Province in 2015 by the Statistical Bureau of Yunnan Province, the total population of Yunnan Province reached 47.368 million. $17.79 \%$ of the total population are 0 to 14 years old, over $73 \%$ are 15 to 64 years old and $8.76 \%$ of the population are above 65 years old ${ }^{4}$. According to Coulmas' theory, (Coulmas, Conrad, Schad-Seifert \& Vogt, 2008) societies can be categorized based on the proportion of people in each age group. In an 'aging society', 7-14\% of the population are 65 years or older. In an 'aged society:' $14-21 \%$ of the population are 65 years or older. In a 'hyper-aged society', $21 \%$ or more of the population are 65 years or older (Coulmas, Conrad, Schad-Seifert \& Vogt, 2008).

Table 3: Age structure of Yunnan Province in the Sixth National Census

\begin{tabular}{c|cc|cc}
\hline \multirow{2}{*}{ Age } & \multicolumn{2}{|c|}{2011} & \multicolumn{2}{c}{2015} \\
\cline { 2 - 5 } & $\begin{array}{c}\text { Population } \\
\text { (million) }\end{array}$ & Percent & $\begin{array}{c}\text { Population } \\
\text { (million) }\end{array}$ & Percent \\
\hline $0-14$ yrs & 9.52 & $20.70 \%$ & 8.43 & $17.79 \%$ \\
$15-64$ yrs & 32.96 & $71.70 \%$ & 34.79 & $73.45 \%$ \\
$\geq 65$ yrs & 3.49 & $7.60 \%$ & 4.15 & $8.76 \%$ \\
Total & 45.97 & $100 \%$ & 47.37 & $100 \%$ \\
\hline
\end{tabular}

Data Source: Statistical Bureau of Yunnan Province website

Yunnan was defined as an 'aging society' (Coulmas, Conrad, Schad-Seifert \& Vogt, 2008) with decreasing numbers of youth. Around $52 \%$ of the population was male and $48 \%$ was female.

Yunnan was China's third poorest province according to gross regional product (GRP) per capita Official rural annual per capita net income recorded in Yunnan in 2015 was 8,242 Yuan (SBYP, $2016 ; 1 U S D=6.88$ Yuan in April, 2017), which is lower than the national average at $\sim 1,566$ USD $^{5}$. Yunnan has few facilities for advanced education. Only one of China's 112 national key universities is in Yunnan (China also has 211 vocational universities and technical colleges). There is also a large gap in educational capacity among the different prefectures, for instance, 48 of the 72 universities and colleges in Yunnan are located in Kunming, whereas Dali has 3, Baoshan has 2, Lincang has 1, but there are none in Diqing and Nujiang ${ }^{6}$. The dropout rate of students in Yunnan

\footnotetext{
${ }^{4}$ http://www.stats.yn.gov.cn/TJJMH_Model/newsview.aspx?id=4269512.

5 www.qqjjsj.com

${ }^{6}$ http://edu.sina.com.cn/gaokao/2016-06-04/doc-ifxsvenv6513007.shtml 
(19\%) was the second highest within China (UNICEF, 2013). About 56.7\% (26.87 million) of the total population of Yunnan lives in rural areas (Statistical Bureau of Yunnan Province, 2016), although seasonal migration may mean that this figure is an underestimate of the true value.

Ethnically, Yunnan is China's most diverse province, with 25 of China's 55 officially recognized minority groups resident in Yunnan. By the end of 2015, the number of people living below the poverty line reached 4.71 million (10\% of total population), which is the second highest of China's provinces ${ }^{7}$. The same study showed that $43.4 \%$ of those in poverty are of minority descent and live in remote areas.

Agricultural land in this mountainous region is unevenly distributed both between and within prefectures. 32.94 million ha of agricultural land was available, of which there are 6.21 million ha of arable land; 23.02 million ha of forest land; 0.147 million ha of rangeland; and 1.93 million ha which has remained as orchards, gardens, etc. Over $80 \%$ of arable land was considered sloping land (Statistical Bureau of Yunnan Province, 2016). In this area, 77\% of the population relied on revenue from agriculture and $70 \%$ of total fiscal revenue was generated from agricultural products (Barton, Fullen, Mitchell, Hocking, Liu et al., 2004). Yunnan produced rice, potatoes, tomato, maize and other crops. Farm practices remain small-scale and lack modern farming technologies. In addition, most cultivable land has been affected by soil erosion, which has contributed to sediment loading of rivers and downstream flooding (Barton, Fullen, Mitchell, Hocking, Liu et al., 2004). Soil erosion has already decreased crop yields by $30-60 \%$ on sloping lands (Barton, Fullen, Mitchell, Hocking, Liu et al., 2004). 59.3\% of the land area of Yunnan is under forest cover ${ }^{8}$, which produces the most diverse and highest quantity of non-forest timber products in China. In recent years, logging has become a major driver of land degradation in Yunnan. One result has been a prolonged drought.

The mountain communities of Yunnan province have little access to technology. Increasing outmigration of youth is creating a brain drain and labour shortage. In these areas, vulnerabilities stemming from climate change can intersect with socio-economic limitations, thus affecting agriculture practices and production, along with water resources, education, social networks and health care. Therefore, it is necessary to study these communities in order to understand the adaptation options that are available to them and to allow these issues to inform local policies for adaptation to climate change.

\footnotetext{
${ }^{7}$ http://news.163.com/16/1209/11/C7RDHAQU000187V5.html
} 


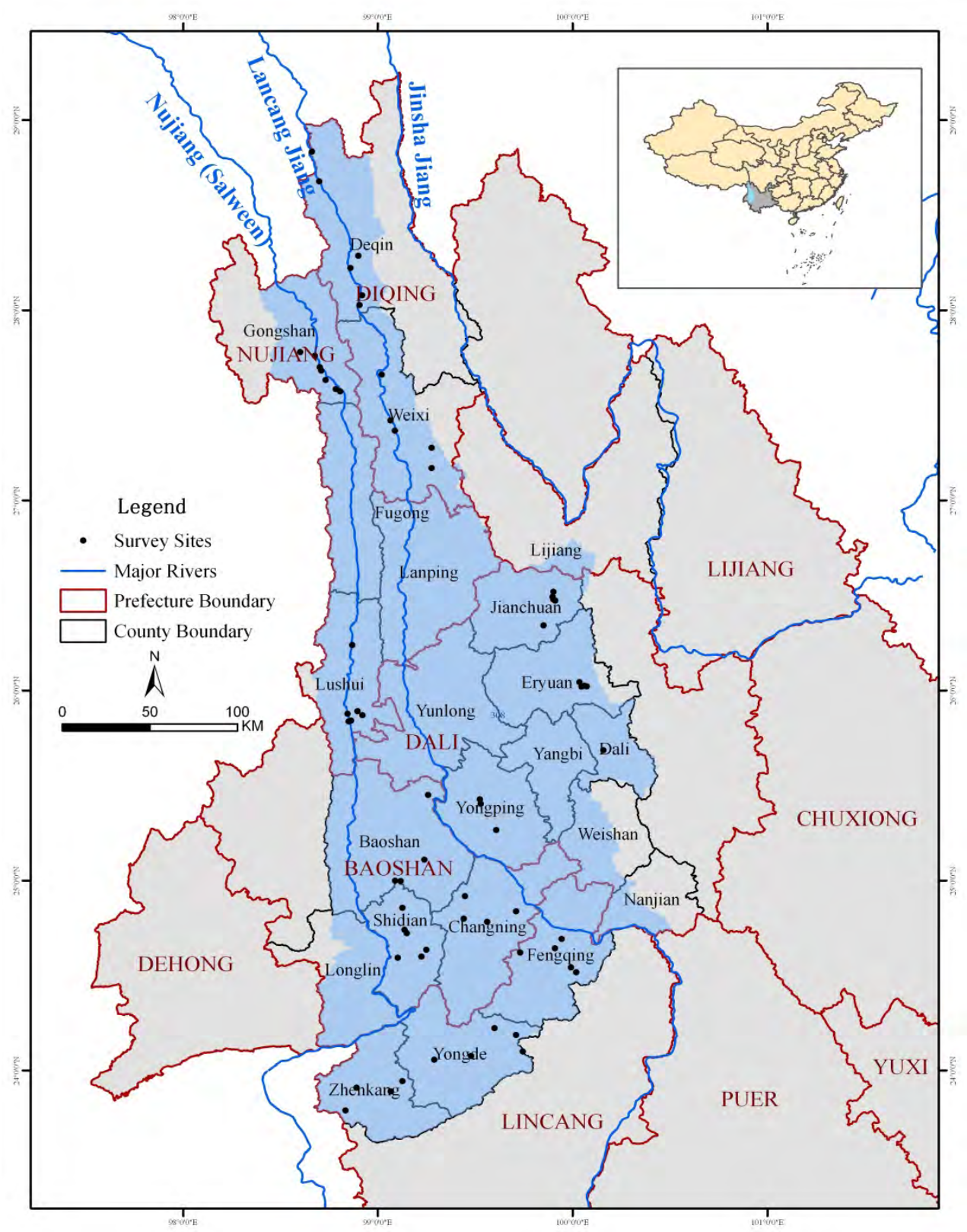

Figure 2: Map of study sites in Yunnan Province

\section{Results}

It should be noted that the survey was conducted with a total of 1950 households in 5 prefectures, and therefore, the results are valid at the prefecture level in the Salween-Mekong basin but not for the whole of Yunnan province or even the whole of the Salween-Mekong basin. However, they do provide an indication about the trends in the basin and the region.

\subsection{Demographic characteristics}

\subsubsection{Age and sex distribution}

The average age of the population varied little among the 5 prefectures, ranging from 42 years in Nujiang to 46 years in Baoshan. In addition, all of the prefectures have aging populations, which 
indicated a probable labour decline, resulting in a heavy burden on the youth. In Baoshan, 15.9\% of the population was over 65 years old, which is categorized as an 'aged society'. In Dali, Diqing and Lincang, $13.6 \%, 12 \%$ and $11 \%$ of the population was over 65 years old respectively, meaning that all are considered an 'aging society' which generally results in an increased burden for younger generations. Nujiang is the only prefecture at the lower boundary of an 'aging society' with only $7 \%$ of the population over 65 years old.

Males and females are equally distributed across Diqing and Nujiang prefectures, whereas the number of males in the population was almost double that of females in Lincang and Baoshan prefecture. Male-headed households were 2.3 times more common than female-headed households in Diqing, and to 13 times more common than female-headed households in Lincang. The highest proportion of female--headed households was recorded in Diqing (30\%), and the lowest was recorded in Lincang (less than $8 \%$ ).

Dali and Diqing, on average, have 4 or more family members per household, while Lincang, Baoshan and Nujiang have on average less than 4 family members per household. Since the survey was administered on rural respondents, and most households have more than one child, the average family size (3.97) is greater than for Yunnan province overall (3.35) (2015 random sampling survey of $1 \%$ of people in Yunnan Province).

In the context of this study, 'dependency ratio' refers to the ratio of people younger than 15 or older than 64 (the dependent members of a household), relative to those aged between 15 and 64 (the productive members). The higher the dependency ratio, the greater the burden productive members are likely to feel. Of all our survey sites, Baoshan had the highest dependency ratio (0.66), while respondents in Nujiang reported 0.37 . The high dependency ratio in Baoshan can be attributed to a comparatively small proportion of working labourers, and a large group of dependents. Dali and Lincang had the next highest dependency ratios (of 0.54 and 0.49 respectively). 


\begin{tabular}{|c|c|c|c|c|c|c|c|}
\hline & Lincang & Baoshan & Dali & Diqing & Nujiang & $\begin{array}{l}\text { Overall } \\
\text { for } 5 \\
\text { Prefectu } \\
\text { res }\end{array}$ & $\begin{array}{l}\text { Yunnan } \\
\text { in } 2015\end{array}$ \\
\hline Number of household members & 3.93 & 3.91 & 4.06 & 4.05 & 3.92 & 3.97 & 3.35 \\
\hline Average Age & 44.4 & 45.9 & 45.6 & 43.69 & 42 & 44.32 & \\
\hline \multicolumn{8}{|l|}{$\begin{array}{l}\text { Age structure of household } \\
\text { members }\end{array}$} \\
\hline$<=5$ years & $8.7 \%$ & $8.6 \%$ & $8 \%$ & $7.7 \%$ & $7 \%$ & $8 \%$ & $17.79 \%$ \\
\hline $6-14$ years & $12.4 \%$ & $15.5 \%$ & $13.40 \%$ & $10.3 \%$ & $12.8 \%$ & $12.88 \%$ & \\
\hline $15-64$ years & $67 \%$ & $60 \%$ & $65 \%$ & $70 \%$ & $73.1 \%$ & $67.02 \%$ & $73.45 \%$ \\
\hline $65+$ years & $11.9 \%$ & $15.9 \%$ & $13.60 \%$ & $12 \%$ & $7 \%$ & $12.08 \%$ & $8.76 \%$ \\
\hline \multicolumn{8}{|l|}{ Sex of household members } \\
\hline Male & $65.90 \%$ & $67.78 \%$ & $55.66 \%$ & $53.58 \%$ & $51.02 \%$ & $58.79 \%$ & $51.48 \%$ \\
\hline Female & $34.10 \%$ & $32.22 \%$ & $44.34 \%$ & $46.42 \%$ & $48.98 \%$ & $41.21 \%$ & $48.52 \%$ \\
\hline \multicolumn{8}{|l|}{ Sex of head of household } \\
\hline Male & $92.11 \%$ & $90.14 \%$ & $83.74 \%$ & $70.12 \%$ & $76.27 \%$ & $82.48 \%$ & \\
\hline Female & $7.89 \%$ & $9.86 \%$ & $16.26 \%$ & $29.88 \%$ & $23.73 \%$ & $17.52 \%$ & \\
\hline Family members / household & $\begin{array}{c}3.97 \pm 1.6 \\
9\end{array}$ & $\begin{array}{c}3.84 \pm 1.5 \\
1\end{array}$ & $\begin{array}{c}4.21 \pm 1.5 \\
8\end{array}$ & $4 \pm 1.57$ & $\begin{array}{c}3.51 \pm 1.4 \\
3\end{array}$ & $\begin{array}{c}3.91 \pm 1.5 \\
6\end{array}$ & \\
\hline Dependency Ratio & 0.49 & 0.66 & 0.54 & 0.42 & 0.37 & 0.50 & \\
\hline
\end{tabular}

Source for Yunnan in 2015: Yunnan Statistical Yearbook 2016.

\subsubsection{Education}

Of all the 5 prefectures, household heads in Dali received the most years of education, with the lowest illiterate population and the greatest $\%$ of the population with 7-12 years of education. In Nujiang, $27 \%$ of household heads were illiterate and only $25 \%$ of household heads had received education for over 7 years. The illiteracy rate in Nujiang was twice the national average. There are several possible explanations for the high illiteracy rate in Nujiang. One possible explanation is the high population of minorities in this region, especially of the Lisu and Bai minorities. Minority groups are more likely to be marginalized due to geophysical and language barriers, as they often live in remote places and speak their own local dialects or languages. The majority of household heads in our survey received education from primary to middle school (that is, between 1 and 9 years of schooling). Dali had the highest rate of higher education (9.8\%), while Lincang had the lowest (2.8\%). Based on the random sampling survey of 2015 for Yunnan Province, the illiteracy rate is $11.5 \% .42 .4 \%$ of heads of households had attended primary school, $29.3 \%$ had attended middle school, 9.6\% had attended high school, and $7.2 \%{ }^{9}$ had attended college/further education (see Table 5 and Figure 3).

${ }^{9}$ http://www.stats.yn.gov.cn/TJJMH_Model/newsview.aspx?id=4269512 
Table 5: Education profile for household heads in this survey

Unit: \% of households

\begin{tabular}{lcccccc}
\hline $\begin{array}{l}\text { Education of the head of } \\
\text { household }\end{array}$ & Lincang & Baoshan & Dali & Diqing & Nujiang & Yunnan \\
\hline Illiterate (0 yrs) & 12.21 & 6.13 & 5.91 & 8.89 & 26.79 & 11.5 \\
Primary school (1-6 yrs) & 57.23 & 46.80 & 33.99 & 50.63 & 47.96 & 42.4 \\
Middle school (7-9 yrs) & 27.72 & 42.45 & 50.25 & 33.33 & 21.17 & 29.3 \\
High school (10-12 yrs) & 2.54 & 4.34 & 9.36 & 6.91 & 4.08 & 9.6 \\
College and above (over 12 yrs) & 0.30 & 0.28 & 0.49 & 0.24 & 0 & 7.2 \\
\hline
\end{tabular}

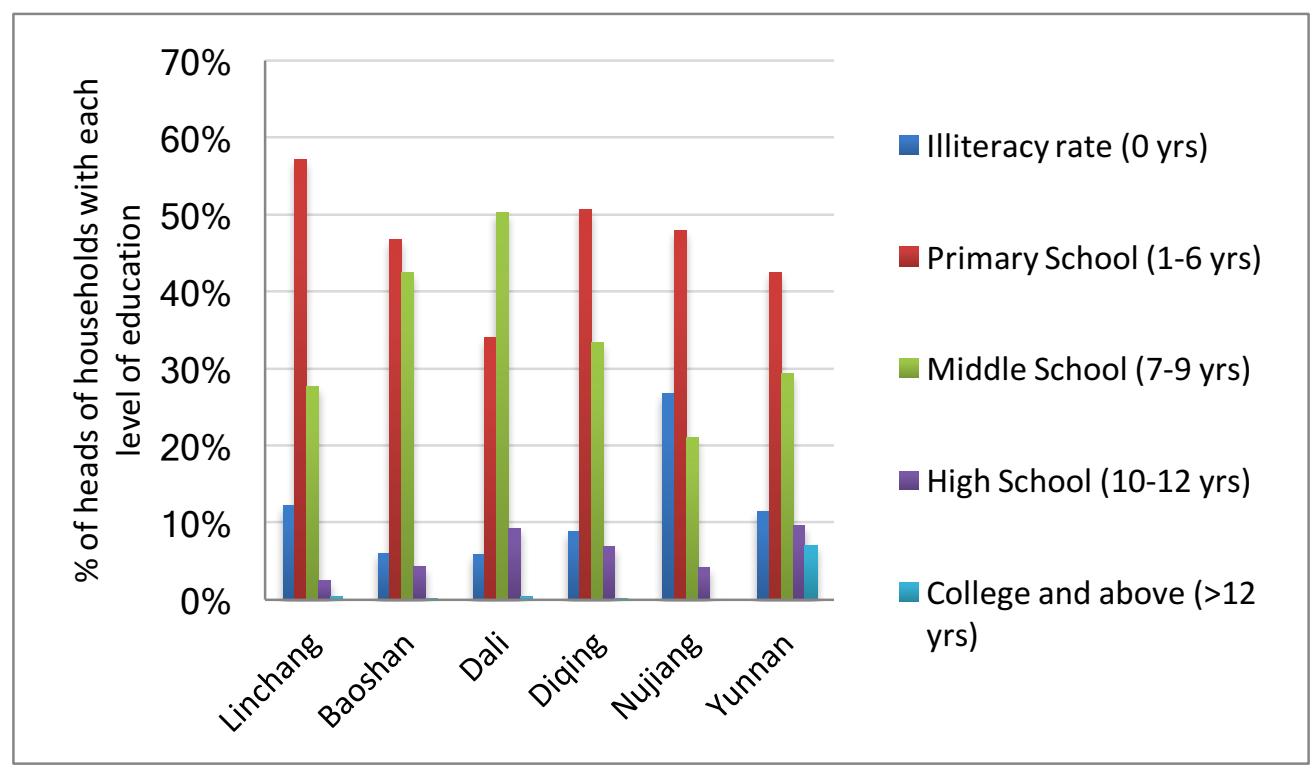

Figure 3: Educational profile of surveyed household heads

\subsubsection{Migration}

Fewer than $1 \%$ of participants reported migrating to another country for work. However, a significant percentage of household members migrated for work to a different region within China. On average, a quarter of family members worked outside of their native village. The exception was Nujiang, which experienced a migration rate of $15 \%$ which is much lower than the other prefectures. There was no difference in the ratio of male and female migrants. Neither geographical location nor gender had a significant effect on migration patterns. Data showed that most migrants preferred longer periods of work at a time, with over half of the migrants having previously been away for over 10 months at a time. Short-term migration (that is, 4-6 months) accounted for $20 \%$ of total migration (see Table 6 ). 
Table 6: PVA index of migration of household members from five prefectures in Yunnan

\begin{tabular}{|c|c|c|c|c|c|}
\hline Migration within China & Lincang & Baoshan & Dali & Diqing & Nujiang \\
\hline Total number of migrants & 384 & 438 & 287 & 268 & 171 \\
\hline $0-3$ months & $9.11 \%$ & $10.73 \%$ & $6.98 \%$ & $4.47 \%$ & $11.11 \%$ \\
\hline 4-6 months & $17.71 \%$ & $16.21 \%$ & $16.72 \%$ & $12.69 \%$ & $25.73 \%$ \\
\hline 7-9 months & $10.68 \%$ & $10.96 \%$ & $12.89 \%$ & $18.29 \%$ & $13.45 \%$ \\
\hline over 10 months & $62.50 \%$ & $62.10 \%$ & $63.41 \%$ & $64.55 \%$ & $49.71 \%$ \\
\hline Total number of male migrants & 216 & 211 & 141 & 144 & 85 \\
\hline $0-3$ months & $5.20 \%$ & $3.42 \%$ & $3.15 \%$ & $2.61 \%$ & $8.19 \%$ \\
\hline 4-6 months & $8.33 \%$ & $7.31 \%$ & $5.92 \%$ & $5.97 \%$ & $9.36 \%$ \\
\hline 7-9 months & $7.29 \%$ & $6.39 \%$ & $9.06 \%$ & $10.45 \%$ & $8.77 \%$ \\
\hline over 10 months & $35.42 \%$ & $31.05 \%$ & $31.01 \%$ & $34.70 \%$ & $23.40 \%$ \\
\hline Total number of female migrants & 168 & 227 & 146 & 124 & 86 \\
\hline $0-3$ months & $3.91 \%$ & $7.31 \%$ & $3.83 \%$ & $1.86 \%$ & $2.92 \%$ \\
\hline 4-6 months & $9.38 \%$ & $8.90 \%$ & $10.80 \%$ & $6.72 \%$ & $16.37 \%$ \\
\hline 7-9 months & $3.39 \%$ & $4.57 \%$ & $3.83 \%$ & $7.84 \%$ & $4.68 \%$ \\
\hline over 10 months & $27.08 \%$ & $31.05 \%$ & $32.40 \%$ & $29.85 \%$ & $26.31 \%$ \\
\hline
\end{tabular}

Although the number of male and female migrants was comparable, there was marked inequality in wages. On average, males in the five prefectures earned USD 422.53 per person per month while females only earned USD 220.79 per person. Migrants from Lincang and Baoshan earned much more than migrants from other prefectures. This is due to the comparatively large proportion of migrants working in small businesses and the construction industry - which are typically better paid. Households in Nujiang had the lowest average earnings with the largest number of people working in service. Females in Lincang earned USD 36.19/month more than males primarily due to a higher proportion of females owning small businesses. In contrast, in Dali, Diqing and Nujiang, males earned twice as much as females (see Figure 4 \& 5).

Table 7: Earnings by gender in each prefecture (USD/month)

\begin{tabular}{|c|c|c|c|c|c|c|c|c|c|c|}
\hline & \multicolumn{2}{|c|}{ Lincang } & \multicolumn{2}{|c|}{ Baoshan } & \multicolumn{2}{|c|}{ Dali } & \multicolumn{2}{|c|}{ Diqing } & \multicolumn{2}{|c|}{ Nujiang } \\
\hline & Male & Female & Male & Female & Male & Female & Male & Female & Male & Female \\
\hline \multicolumn{11}{|l|}{ Total money } \\
\hline $\begin{array}{l}\text { earned by } \\
\text { migrants from }\end{array}$ & 92782.85 & 78341.26 & 144412.69 & 48238.09 & 45309.52 & 13246.03 & 35269.84 & 17063.49 & 19063.49 & 8984.12 \\
\hline each prefecture & & & & & & & & & & \\
\hline Earnings Per & & & & & & & & & & \\
\hline & 429.52 & 465.71 & 684.28 & 215.39 & 308.25 & 90.79 & 244.92 & 137.61 & 224.28 & 104.44 \\
\hline
\end{tabular}


Figure 4: Total remittances per person per year from employment migration (USD)

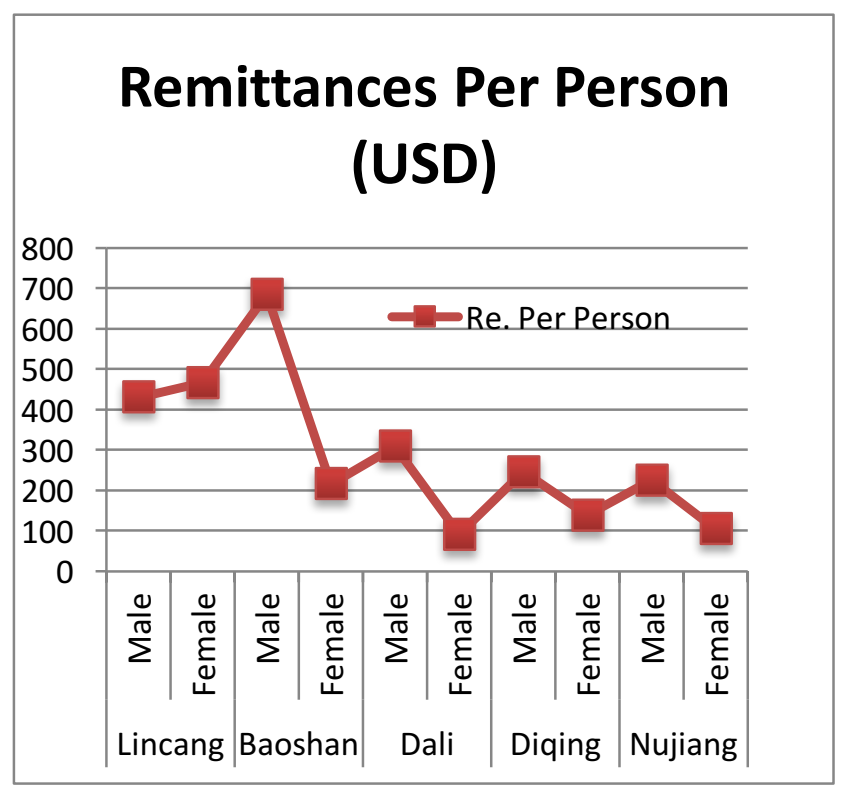

Figure 5: Total remittances per year from employment migration (USD)

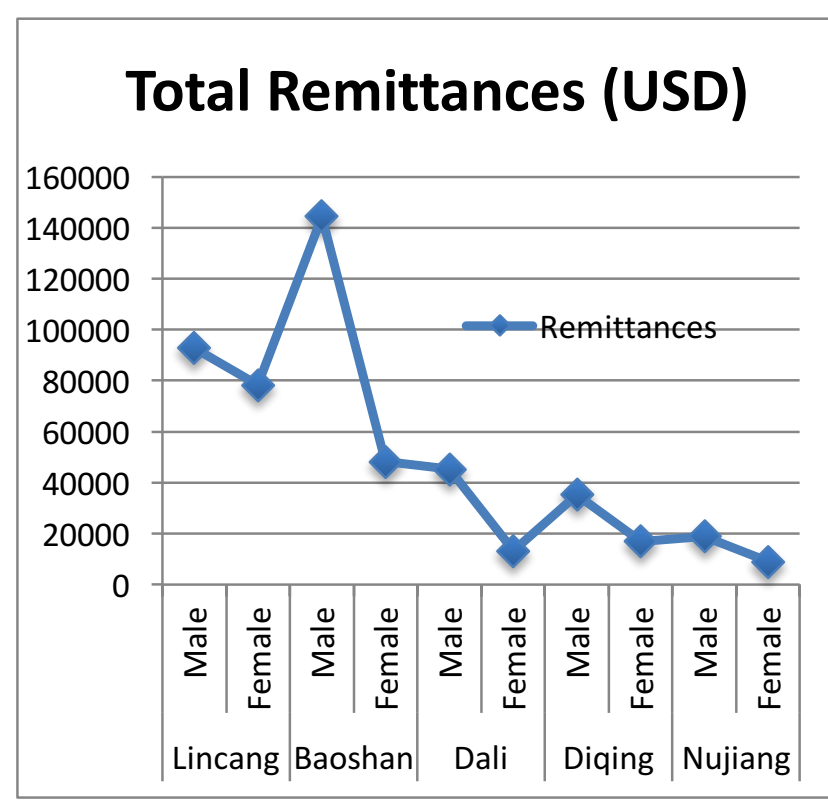

\subsection{Socio-economic Status (SES)}

\subsubsection{Housing}

Durability of the materials with which houses are constructed influence the longevity of the house, and thus the financial burden of maintaining a house over time. In descending order of durability, available building materials are concrete, fired bricks, wood/branches, unfired bricks, and finally mud. The cost of these materials varies little across China. In this survey, the three most commonly used construction materials for exterior walls were reported to be fired bricks, unfired bricks, and mud. Throughout the 5 prefectures, fired bricks were the most common material for exterior walls apart from in Diqing where unfired bricks were more frequently used.

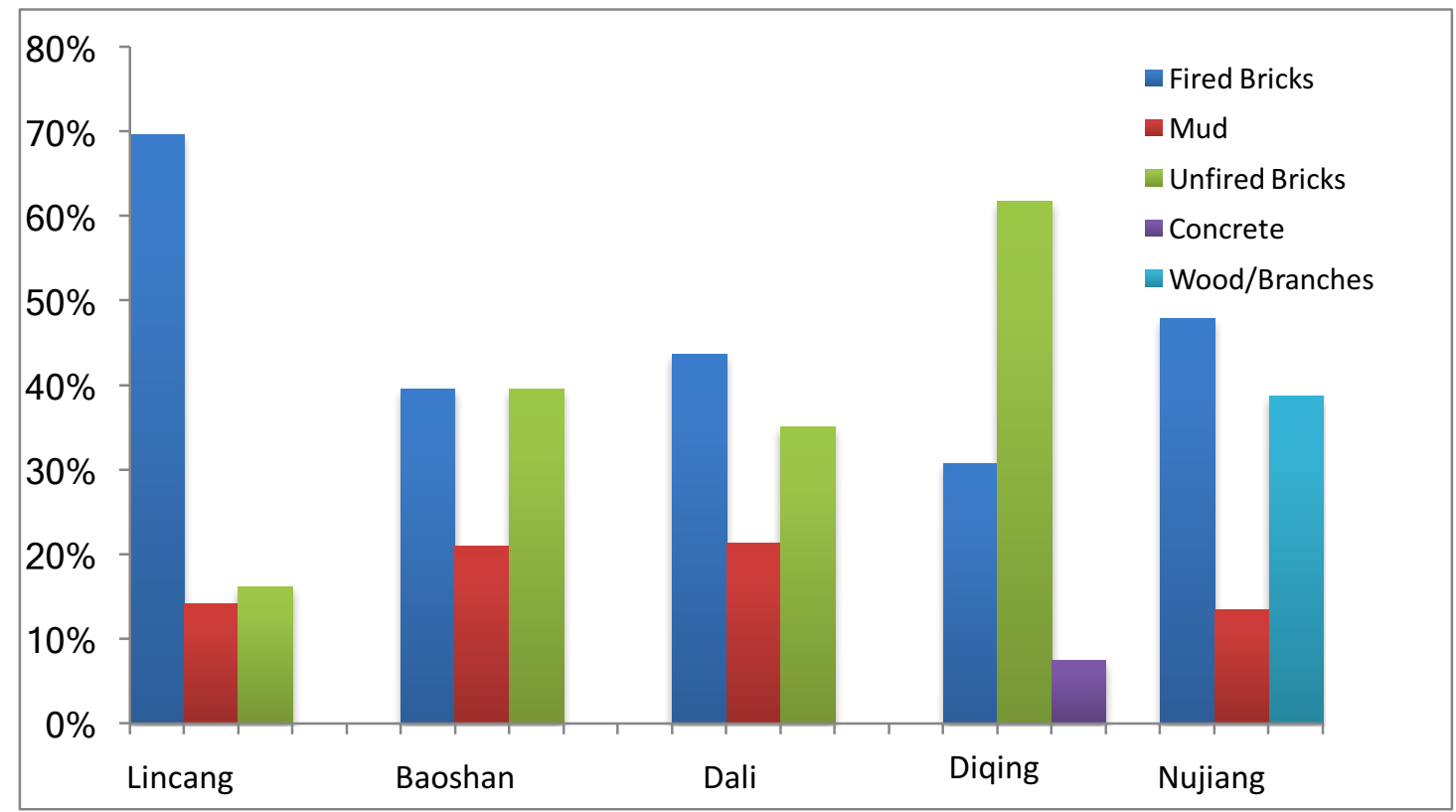

Figure 6: Materials for exterior wall in five prefectures 
In rural areas, the main roofs of houses were usually tiled. In Dali, 70\% of households used tiles. $60 \%$ of households in Diqing used tiles, but if possible, householders would have preferred to use metal (See Figure 7).

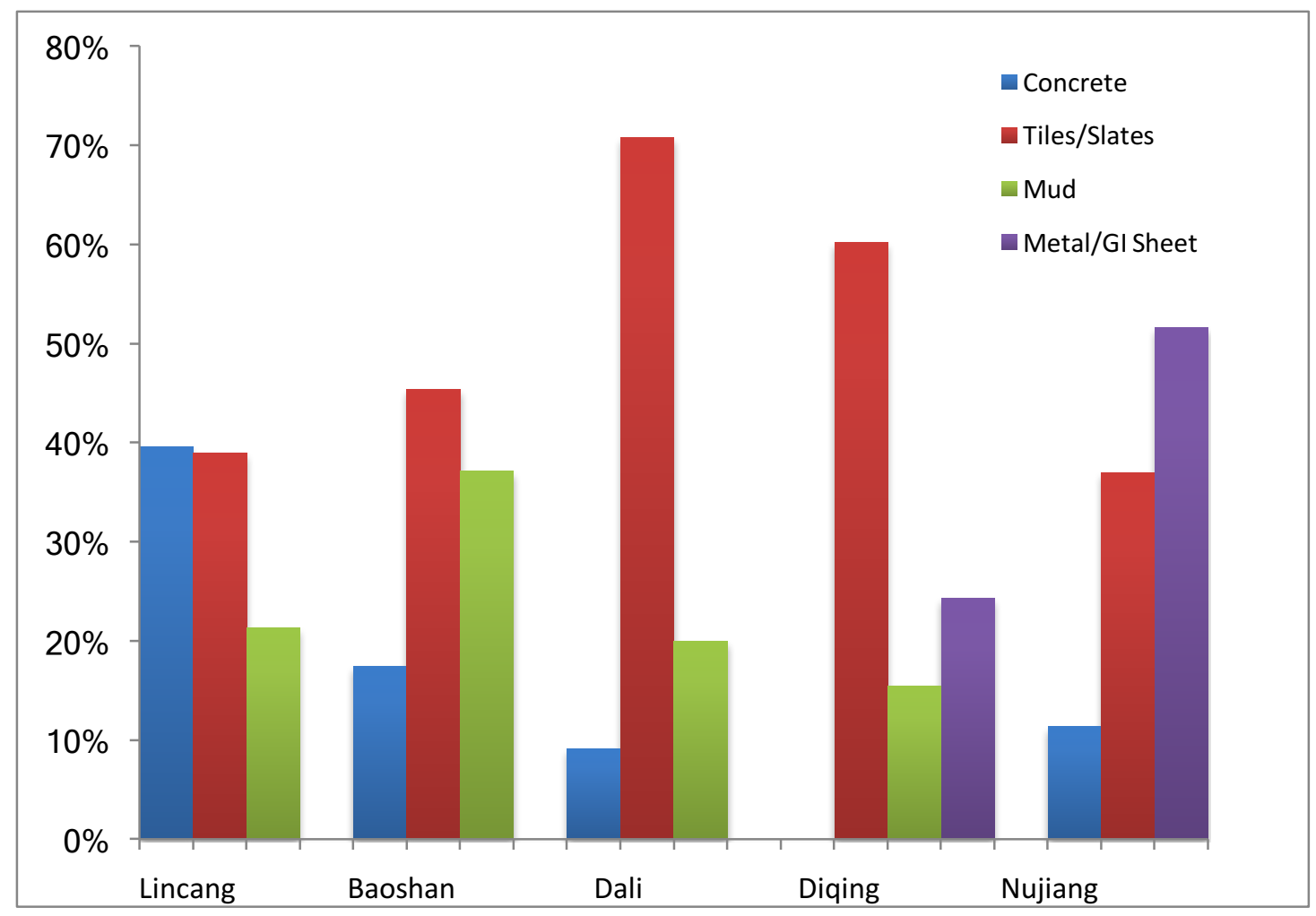

Figure 7: Materials for the main roofs of the houses in five prefectures

For the purpose of analysis, housing materials were divided into 4 categories of durability, which ranged from 1 (the strongest) to 4 (the weakest). These categories were based on a combination of both exterior wall and main roof materials. Values were assigned to materials based on their resistance to damage, using a standardized method. Lower numbers indicated greater resistance to damage. Dali had the most durable housing (2.18), followed by Diqing (1.94), and Nujiang (1.85). Households in Lincang (1.69) and Baoshan (1.61) were more vulnerable to severe weather and more prone to damage.

\subsubsection{Size of houses}

The number of rooms within a household varied greatly across locations. On average, households in Lincang and Baoshan had 4 rooms, while households in Diqing were nearly twice the size, having an average of 7 rooms.

In economic terms, the 'willingness to pay' is a measure of the maximum amount a consumer thinks a product or service is worth. In this study, we defined the term 'expected value' as a reflection of the minimum amount a seller thinks their product or service was worth. 'Expected rental value' is the minimum amount that an owner would expect to receive for renting out their property. In terms of 'expected rental value', male respondents tended to estimate a higher value than females, except in Baoshan and Nujiang. The largest gender gap was recorded in Dali. Male-headed households in Dali asked for USD 127.3 more than women for renting the same 
house. The attributed value of a house was partly affected by gender, but primarily determined by the size and location of the house. The more rooms the proprietor has, the more money the renter has to pay. The price for renting a house in Dali and Diqing is over twice that of Baoshan and Nujiang, because households in Dali and Diqing generally have more rooms (See Table 5). This is because of the higher number of tourists in these areas which has resulted in inflated house prices.

Table 8: Average number of rooms per household and cost per house per month to rent

\begin{tabular}{cccccc}
\hline \multicolumn{1}{c}{ Lincang } & Baoshan & Dali & Diqing & Nujiang \\
\hline No. of rooms & 3.75 & 3.98 & 5.76 & 7.03 & 4.64 \\
Payment for the house (Price/room/month) & & & \\
Male & 96.19 & 84.92 & 296.98 & 279.68 & 129.36 \\
Female & 94.92 & 86.50 & 169.68 & 251.11 & 130.15 \\
\hline
\end{tabular}

\subsubsection{Access of households to agricultural land}

Yunnan lies in a mountainous area, stretching across both high and low elevations with a range in altitude of $6700 \mathrm{~m}(\sim 22,000 \mathrm{ft})$. With such diverse topology, the prefectures vary not only in land area and elevation [ranging from 1.458 million ha (Nujiang) to 2.83 million ha (Dali)] (SBYP, 2016: 459), but also in the proportion of that land that is suitable for agriculture. We chose our study areas to encompass these various land types. While the overall average was 0.88 ha cultivated land per household based on the survey data, households in Lincang had the largest amount of agricultural land, on average 1.32 ha per household, which was significantly larger than the plots in other prefectures, especially in comparison to households in Diqing, who reported 0.42 ha (excluded land used to graze livestock) on average. Although geographic constraints meant arable land was divided into small patches, there was no correlation between the land size and the number of plots a household owns. In Lincang, Baoshan and Diqing, agricultural land was most commonly used for growing crops. Lincang, Nujiang and Baoshan are located in southwest Yunnan, and each have a greater land area than Dali and Diqing. The average plot size in Lincang and Nujiang was twice the size of plots in Dali and Diqing. 95\% of agricultural land in this study was used for crop farming and orchards (See Table 9).

Table 9: Average plot size per household in each of five prefectures

\begin{tabular}{cccc}
\hline Prefectures & $\begin{array}{c}\text { Cultivated land } \\
\text { (ha)/household } \\
\text { (surveyed areas) }\end{array}$ & $\begin{array}{c}\text { Total Agricultural Land in } \\
\text { the five prefectures of } \\
\text { Yunnan (million ha) }\end{array}$ & $\begin{array}{c}\text { Agricultural land } \\
\text { (ha)/household in the } \\
\text { five prefectures }\end{array}$ \\
\hline Lincang & 1.316 & 2.15 & 3.26 \\
Baoshan & 0.898 & 1.70 & 2.43 \\
Dali & 0.61 & 2.49 & 2.34 \\
Diqing & 0.416 & 1.83 & 18.89 \\
Nujiang & 1.149 & 1.19 & 7.59 \\
\hline
\end{tabular}

Source: Figures on total agricultural land and agricultural land per person (calculated) are from 'Yunnan Statistical Yearbook 2016' (SBYP, 2016: 463 \& 380). 
The average plot sizes per household are quite different between surveyed area and statistics, it may be because the land classification standard is different. The surveyed plot sizes may refer to the cultivated land, but the statistics data includes all of the land for agricultural use. Please see the difference between agricultural land and cultivated land at provincial level in Table 10 (there is no data available at prefectural level).

Table 10: Land utilization in Yunnan (2015)

\begin{tabular}{lcc}
\hline Item & Area (Million ha) & Proportion of Total Area (\%) \\
\hline Land Survey Area & 38.319 & 100.0 \\
\hline Agricultural Land & 32.944 & 86.0 \\
\hline Cultivated Land & 0.62 & 16.2 \\
\hline
\end{tabular}

Note: Data in this table were obtained from the $\mathbf{2 0 1 5}$ land changing survey of the second land survey, which is different from the detailed land survey before 2008 in terms of land classification standard, technical standards and investigation methods. Source: Yunnan Statistical Yearbook 2016 (SBYP, 2016: 459).

Nujiang and Dali had the highest proportion of respondents (10\%) who claimed they had no access to agricultural land. Possible factors that could have affected traditional access to agricultural land are landslides, migration and reliance on non-agricultural sources of income. In Nujiang, 10\% of respondents claimed that they had no access to land because of severe landslides that led to passive migration. In Dali, $14 \%$ of respondents claimed that they did not cultivate their agricultural land anymore, because they have rented out their land to others, and now rely on tourism and investments for their household income. Around $8 \%$ of respondents from Lincang expressed that they would seek job opportunities in non-agricultural sectors. However, the percentage of households abandoning their land is generally low.

\subsubsection{Livestock assets}

Livestock ownership varied across prefectures. Lincang households possessed the largest herds of pigs and horse/donkey/mules, while Dali had more poultry. Diqing had the largest number of cattle, while Nujiang had the largest flocks of goats and/or sheep (see Figure 8). There is no difference between households engaged in agriculture ( $99 \%$ ) and those that own livestock ( $\sim 8 \%$ ). The difference lies in the number of livestock assets, and different types of agricultural activities. 


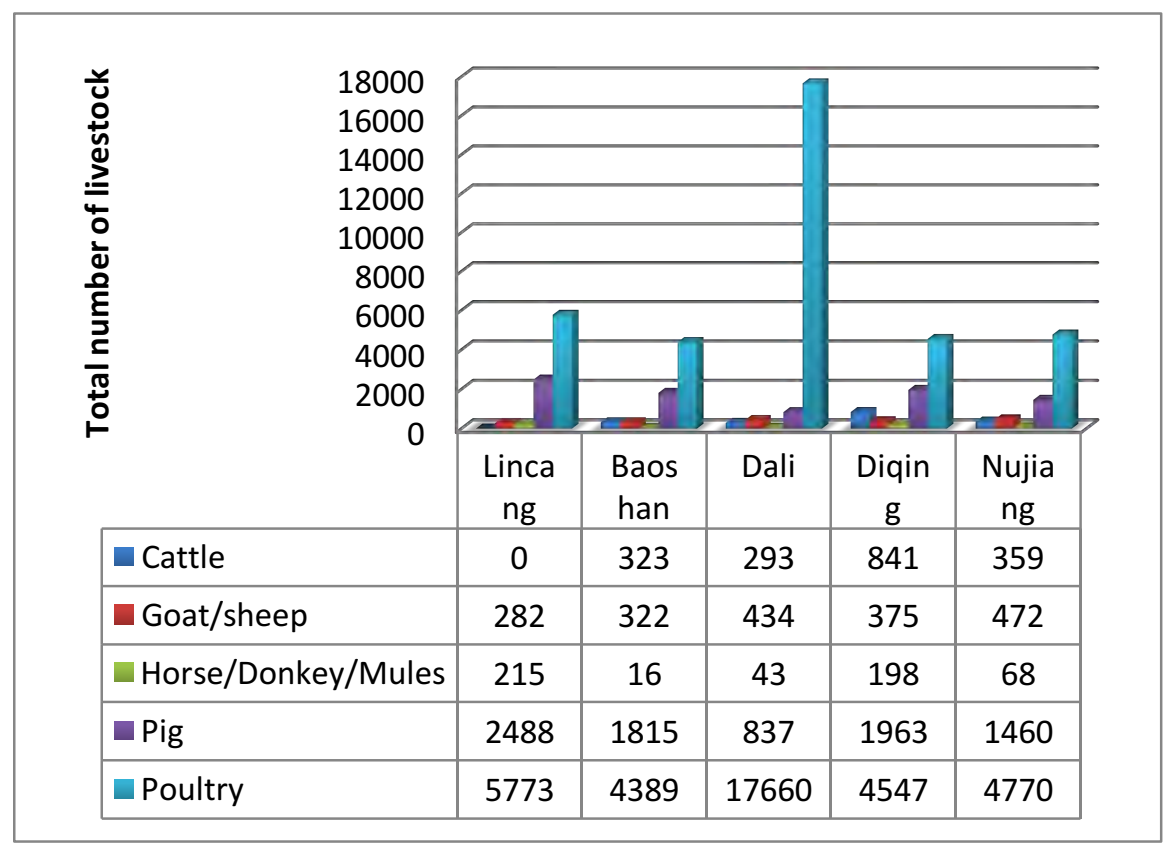

Figure 8: Total livestock assets by prefecture

\subsubsection{Appliance assets}

Based on past surveys, we believed that the number of motor vehicles would be a reliable indicator of appliance assets of households. Other possible asset indicators are too common and their variation in size and relatively low market values would limit their usefulness in representing all such assets owned by a given household. Overall, there are 79 motor vehicles per 100 households in 5 prefectures with Baoshan and Dali having the highest number of motor vehicles per 100 households, namely, 97 and 93 respectively. The number of motor vehicles could be interpreted in two ways: 1) it could reflect purchasing power, or 2) poor roads in combination with lack of sufficient public transportation lead to a greater need of privately owned motor vehicles for transportation (see Table 11).

Table 11: The number of motor vehicles in surveyed areas

\begin{tabular}{cccccc}
\hline & Lincang & Baoshan & Dali & Diqing & Nujiang \\
\hline Number of motor vehicles & 297 & 380 & 379 & 326 & 195 \\
\hline
\end{tabular}

\subsection{Livelihoods}

\subsubsection{Sources of income}

Income structure was diverse, yet there were some general trends. Generally, the main sources of income were daily wages, sale of agricultural products and sale of livestock products. Daily wages accounted for a quarter of household income across prefectures except in Diqing (19.24\%). Income generated from the sale of agricultural products accounted for another quarter of income in all areas, except Nujiang (only 9.3\%). Fifteen percent of income was generated through the sale of livestock and livestock products. Unlike in other prefectures, business revenue or trade income in Dali and Diqing 
contributed $18 \%$ and $13 \%$ of income respectively. The income structure in Nujiang was different from that for other areas; the main source of income was daily wages, government social benefit schemes, and the sale of livestock and related products. Throughout the study area, income generated by tourism, pensions or sale of herb was very limited (See Table 12).

Table 12: Main sources of income for surveyed prefectures

\begin{tabular}{lcccccc}
\hline Source of income & Lincang & Baoshan & Dali & Diqing & Nujiang & Overall \\
\hline $\begin{array}{l}\text { Agricultural product } \\
\text { (crops/vegetables/fruits) sales }\end{array}$ & $30.13 \%$ & $28.24 \%$ & $21.38 \%$ & $20.98 \%$ & $9.30 \%$ & $22.01 \%$ \\
$\begin{array}{l}\text { Livestock \& livestock product } \\
\text { sales }\end{array}$ & $16.59 \%$ & $15.16 \%$ & $10.45 \%$ & $14.44 \%$ & $13.03 \%$ & $13.93 \%$ \\
Daily wage & $24.79 \%$ & $26.06 \%$ & $26.90 \%$ & $19.24 \%$ & $27.62 \%$ & $24.92 \%$ \\
Salaried employment & $4.37 \%$ & $6.81 \%$ & $9.45 \%$ & $7.07 \%$ & $6.50 \%$ & $6.84 \%$ \\
Other business/trade income & $3.12 \%$ & $7.28 \%$ & $18.19 \%$ & $13.41 \%$ & $4.77 \%$ & $9.35 \%$ \\
Remittances & $8.39 \%$ & $9.23 \%$ & $2.34 \%$ & $3.04 \%$ & $2.12 \%$ & $5.02 \%$ \\
Governmental social benefits & $2.31 \%$ & $1.58 \%$ & $3.12 \%$ & $3.08 \%$ & $16.19 \%$ & $5.26 \%$ \\
\hline
\end{tabular}

\subsubsection{Household patterns of consumption and expenditure}

Household expenditure was evaluated using the consumption and purchasing patterns of the 30 days prior to the day of the survey. Generally, households in Lincang, Baoshan and Nujiang spent around USD 220 each on average during this 30-day period. Households in Dali spent a little more (approximately USD 260) than other prefectures, while households in Diqing consumed far more, reaching USD 358 in the month prior to the commencement of the survey (See Table 13).

By dividing the total value of food consumption into sub-categories, our survey data revealed that grains, meats and vegetables accounted for half of all household consumption. Around $12 \%$ of the total value of consumption was spent on cigarettes. Respondents spent six times more on cigarettes than on alcohol (See Table 13).

Table 13: Total value of food consumption, cigarette and alcohol purchases per month per household (USD) in surveyed prefectures

\begin{tabular}{lcccccc}
\hline $\begin{array}{l}\text { Expenditure on food } \\
\text { consumption, cigarette and } \\
\text { alcohol purchases }\end{array}$ & Lincang & Baoshan & Dali & Diqing & Nujiang & Overall \\
\hline Grains & 41.7 & 46.1 & 38.0 & 69.6 & 35.9 & 46.26 \\
Meat & 44.9 & 58.4 & 51.0 & 63.7 & 52.3 & 54.06 \\
Vegetable & 19.5 & 22.2 & 25.4 & 20.5 & 17.8 & 21.08 \\
Cigarettes & 36.8 & 31.6 & 40.2 & 48.3 & 26.4 & 36.66 \\
Meals outside & 7.9 & 7.3 & 28.3 & 32.7 & 20.8 & 19.4 \\
Cooking oil & 13.8 & 14.3 & 16.0 & 21.3 & 16.4 & 16.36 \\
Fresh fruits & 13.9 & 13.9 & 16.8 & 14.6 & 11.0 & 14.04 \\
Spices & 5.3 & 4.9 & 5.7 & 7.5 & 4.8 & 5.64 \\
Sugar & 9.5 & 8.2 & 9.3 & 14.1 & 7.2 & 9.66 \\
Alcohol & 7.7 & 3.6 & 5.6 & 14.1 & 12.0 & 8.6
\end{tabular}




\begin{tabular}{lcccccc}
\hline $\begin{array}{l}\text { Expenditure on food } \\
\text { consumption, cigarette and } \\
\text { alcohol purchases }\end{array}$ & Lincang & Baoshan & Dali & Diqing & Nujiang & Overall \\
\hline Bread & 3.4 & 2.3 & 6.1 & 12.3 & 5.1 & 5.84 \\
Other expenditure & 0.9 & 0.5 & 11.4 & 20.3 & 9.0 & 8.42 \\
Milk & 7.1 & 5.4 & 8.6 & 14.7 & 5.1 & 8.18 \\
Pulses, lentils, beans & 3.1 & 2.6 & 4.6 & 4.6 & 2.7 & 3.52 \\
Total & $\mathbf{2 1 5 . 5}$ & $\mathbf{2 2 1 . 3}$ & $\mathbf{2 6 7 . 1}$ & $\mathbf{3 5 8 . 2}$ & $\mathbf{2 2 6 . 6}$ & $\mathbf{2 5 7 . 7 4}$ \\
\hline
\end{tabular}

Households in Lincang, Baoshan and Dali spent one-fifth of their total income on health-related expenditures, while households in Diqing and Nujiang spent one third of their total income, due to the high frequency of illness, especially for households in Nujiang.

For households in Lincang, over $60 \%$ of income was spent on medical expenses, agricultural tools, festivals and transportation. The same pattern of expenditure could be observed in Baoshan; however, Baoshan's households spent more on education than transportation costs. In Dali, medical expenses, celebrations, veterinary expenses and agricultural tools constituted a major part of non-food expenditures (about 63\%). In Diqing, medical, transportation, education and celebrations were the largest expenses (about 57\%). The situation was similar in Nujiang, except that clothing was also a major expense (See Table 14). In general, food consumption, cigarette and alcohol purchases and other non-food expenditures accounted for half of total expenditures (see Table 15).

Table 14: Total monthly expenditure on non-food items (USD) per households in surveyed prefectures

\begin{tabular}{l|cc|cc|cc|cc|cc}
\hline Expenditure on non-food items & Lincang & \% & Baoshan & \% & Dali & \% & Diqing & \% & Nujiang & \% \\
\hline Medical expenses & 44.5 & 17.3 & 63.4 & 18.9 & 80.3 & 22.1 & 111.4 & 29.6 & 86.4 & 35.9 \\
Education & 24.3 & 9.5 & 41.9 & 12.5 & 38.6 & 10.6 & 47.7 & 12.7 & 22.8 & 9.5 \\
Clothing & 15.9 & 6.2 & 19.3 & 5.8 & 29.6 & 8.1 & 40.1 & 10.6 & 23.1 & 9.6 \\
Personal care items & 6.1 & 2.4 & 5.5 & 1.6 & 6.9 & 1.9 & 7.4 & 2.0 & 4.7 & 2.0 \\
Fuels \& electricity & 6.6 & 2.6 & 11.6 & 3.5 & 12.8 & 3.5 & 15.1 & 4.0 & 14.2 & 5.9 \\
Transportation & 32.6 & 12.7 & 38.1 & 11.4 & 39.9 & 11.0 & 53.9 & 14.3 & 31.5 & 13.1 \\
Agricultural tools & 40.6 & 15.8 & 64.6 & 19.3 & 42.6 & 11.7 & 26.5 & 7.0 & 13.8 & 5.7 \\
Veterinary expenses & 27.3 & 10.6 & 27.2 & 8.1 & 42.9 & 11.8 & 22.4 & 5.9 & 14.4 & 6.0 \\
Celebrations & 38.1 & 14.8 & 45 & 13.4 & 64.3 & 17.7 & 46.8 & 12.4 & 28.4 & 11.8 \\
Miscellaneous expenditure & 20.9 & 8.1 & 18.8 & 5.6 & 5.7 & 1.6 & 5.2 & 1.4 & 1.7 & 0.7 \\
Total & $\mathbf{2 5 6 . 9}$ & $\mathbf{1 0 0}$ & $\mathbf{3 3 5 . 4}$ & $\mathbf{1 0}$ & $\mathbf{3 6 3 . 6}$ & $\mathbf{1 0 0}$ & $\mathbf{3 7 6 . 6}$ & $\mathbf{1 0 0 \%}$ & $\mathbf{2 4 1}$ & $\mathbf{1 0 0 . 0}$ \\
\hline
\end{tabular}

Table 15: Total monthly expenditure per household (USD) in surveyed prefectures

\begin{tabular}{lcccccccccc}
\hline Monthly Expenditure & Lincang & $\%$ & Baoshan & $\%$ & Dali & $\%$ & Diqing & $\%$ & Nujiang & $\%$ \\
\hline $\begin{array}{l}\text { Food items, cigarettes and } \\
\text { alcohol }\end{array}$ & 215.5 & 46 & 221.3 & 40 & 267.1 & 42 & 358.2 & 49 & 226.6 & 48 \\
Non-food items & 256.9 & 54 & 335.4 & 60 & 363.6 & 58 & 376.6 & 51 & 241 & 52 \\
Total & $\mathbf{4 7 2 . 4}$ & $\mathbf{1 0 0}$ & $\mathbf{5 5 6 . 7}$ & $\mathbf{1 0 0}$ & $\mathbf{6 3 0 . 7}$ & $\mathbf{1 0 0}$ & $\mathbf{7 3 4 . 7}$ & $\mathbf{1 0 0}$ & $\mathbf{4 6 7 . 6}$ & $\mathbf{1 0 0}$ \\
\hline & & & & 22 & & & & & &
\end{tabular}




\subsubsection{Forestry and non-timber forest products (NTFPs)}

In this survey, $5 \%$ of households in Nujiang reported timber extraction (either carried out themselves or by others in their area), which was the greatest percentage for any of the prefectures. In contrast, firewood collecting by each household was widespread in all five prefectures. Over $80 \%$ of households in Lincang and Diqing reported that they collected firewood, with $78 \%$ of households in Nujiang collecting firewood, $58 \%$ in Baoshan, $30 \%$ in Dali.

Foraging is also important for households in rural Yunnan. Most households in the study area collected wild edible vegetables, including mushrooms and fruits from the forests. Generally, more households collected wild edible vegetables than collected wild edible fruits. A few households hunted wild game and collected reed/cane, thatch, mud/stone, medical plants and wooden poles. Collecting fodder was an important activity in all areas. Half of all households collected fodder, and a quarter of households reported collecting forage/grass. In contrast, there was wide variation in prevalence of dried litter collection, ranging from $45 \%$ of households in Diqing to $2 \%$ in Lincang (see Table 16 ).

Table 16: Forests and NTFPs in five prefectures

\begin{tabular}{lccccc} 
& & & & Unit: $\mathrm{kg} / \mathrm{household}$ \\
\hline \multicolumn{1}{c}{ Forests and NTFPs } & Lincang & Baoshan & Dali & Diqing & Nujiang \\
\hline Timber & 8 & 0 & 4 & 15 & 18 \\
Branches & 5 & 2 & 0 & 17 & 7 \\
Firewood & 313 & 228 & 123 & 329 & 306 \\
Wild edible veg. & 59 & 25 & 7 & 21 & 17 \\
Wild edible fruits & 5 & 1 & 2 & 4 & 4 \\
Dried litter & 5 & 8 & 80 & 152 & 52 \\
Foliage & 10 & 10 & 16 & 13 & 6 \\
Fodder & 237 & 262 & 139 & 192 & 233 \\
Forage & 72 & 113 & 79 & 142 & 71 \\
Bamboo & 63 & 21 & 15 & 2 & 9 \\
Reed/cane & 5 & 0 & 1 & 0 & 0 \\
Thatch & 3 & 0 & 4 & 0 & 1 \\
Mud/stone & 13 & 2 & 11 & 19 & 8 \\
Medicinal plants & 26 & 3 & 0 & 17 & 5 \\
Poles/shaft & 4 & 0 & 1 & 2 & 0 \\
Wild game & 2 & 1 & 0 & 0 & 0 \\
\hline
\end{tabular}

\subsubsection{Farming practices}

Yunnan has many minority ethnic groups and a vast mountainous area. In these areas, $77 \%$ of the population relied on revenue from agriculture and $70 \%$ of total fiscal revenue was generated from agricultural products (Barton, Fullen, Mitchell, Hocking, Liu et al., 2004). Yunnan produced rice, potatoes, tomato, maize and various minor crops. Farm practices have continued to be small-scale and lack modern farming technologies. In Yunnan, most cultivable land has been affected by soil erosion, which has contributed to sediment loading of the Yangtze River and 
downstream flooding (Barton, Fullen, Mitchell, Hocking, Liu et al., 2004). Soil erosion has decreased crop yields by $30-60 \%$ on sloping land (Barton, Fullen, Mitchell, Hocking, Liu et al., 2004).

Yunnan's agricultural production is vulnerable to climate change for several reasons. The large agricultural population depletes natural resources. Production areas have complex and deteriorating topography. Achieving sustainable agriculture during a period of climate change will be a challenge for most households in Yunnan.

Over $90 \%$ of surveyed households planted less than three types of staple crops (with the exception of Baoshan). Around half of respondents in Dali claimed that they planted only one staple crop. Less than $4 \%$ of households in our study planted five or more staple crops: $3 \%$ of Baoshan's households, $2 \%$ of Lincang's households, and $1 \%$ of Nujiang's households (see Table 17). Only Lincang (4\%) and Baoshan (2\%) households planted five or more types of cash crops. Around $90 \%$ of households in Dali, Diqing, and Nujiang planted two or fewer types of cash crops, while $70 \%$ of households in Lincang and Baoshan planted two or fewer types of cash crops (see Table 18).

Table 17: Number of staple crops planted across five prefectures

\begin{tabular}{lccccc}
\hline No. of staple crops & Lincang & Baoshan & Dali & Diqing & Nujiang \\
\hline One & $34 \%$ & $29 \%$ & $48 \%$ & $33 \%$ & $35 \%$ \\
Two & $42 \%$ & $42 \%$ & $34 \%$ & $47 \%$ & $38 \%$ \\
Three & $18 \%$ & $18 \%$ & $13 \%$ & $18 \%$ & $18 \%$ \\
Four & $4 \%$ & $8 \%$ & $5 \%$ & $2 \%$ & $8 \%$ \\
Five and above & $2 \%$ & $3 \%$ & 0 & 0 & $1 \%$ \\
Total & $100 \%$ & $100 \%$ & $100 \%$ & $100 \%$ & $100 \%$ \\
\hline
\end{tabular}

Table 18: Number of cash crops planted across five prefectures

\begin{tabular}{lccccc}
\hline No. of cash crops & Lincang & Baoshan & Dali & Diqing & Nujiang \\
\hline One & $24 \%$ & $48 \%$ & $67 \%$ & $54 \%$ & $45 \%$ \\
Two & $52 \%$ & $35 \%$ & $29 \%$ & $37 \%$ & $43 \%$ \\
Three & $18 \%$ & $12 \%$ & 4 & $9 \%$ & $9 \%$ \\
Four & $4 \%$ & $3 \%$ & 0 & 0. & $3 \%$ \\
Five and above & $2 \%$ & $2 \%$ & 0 & 0 & 0 \\
Total & $100 \%$ & $100 \%$ & $100 \%$ & $100 \%$ & $100 \%$ \\
\hline
\end{tabular}

In Yunnan, cultivation of crops was affected by a series of factors, including topography and local customs. The most common crop was summer maize, apart from in Dali, where rice was more common. From 2003-2013, the total area sown with maize, mostly summer maize, increased from 1.06 million ha to 1.45 million and which resulted in 1.75 times the maize yield, from 3.99 million tons to 7 million tons (Data Centre of China Grain, 2015). At the same time the production of maize per hectare increased from $3735 \mathrm{~kg}$ to $4800 \mathrm{~kg}$. In 2003, the total area sown with rice increased from 1.04 million to 1.08 million ha, but by 2009 had dropped to 1.01 million. 
Eventually, rice production increased to 1.08 million ha by 2013. The total production of rice increased by $5 \%$ over the past 10 years; from 6.39 million tons to 6.68 million tons. The mean unit production per hectare in Yunnan decreased from $6090 \mathrm{~kg}$ in 2003 to $5940 \mathrm{~kg}$ in 2013.

\subsection{Access to social networks}

\subsubsection{Access to credit}

Over $60 \%$ of respondents claimed that it was easy to borrow money while around $19 \%$ reported that they found it difficult to borrow money. Only $5 \%$ claimed great difficulty in borrowing money. With the exception of Diqing (where fewer households borrowed money), neither gender nor location of the borrower affected access to credit.

The level of indebtedness of households differed between prefectures. Diqing and Nujiang had the lowest percentage of households with debt. At least $68 \%$ of households in these sites claimed to have no debt while half of the households in Baoshan and Lincang reported having some debt. Twenty percent of households in Baoshan reported having a lot of household debt; in contrast only $7 \%$ of households in Diqing had a lot of debt (see Table 19). These categories were based on the perception of households, and not on actual debt financial data.

Table 19: Debt status of households in surveyed prefectures

\begin{tabular}{lcccc}
\hline \multicolumn{1}{c}{ Debt } & None & A little & Moderate & A lot \\
\hline Lincang & $53 \%$ & $6 \%$ & $21 \%$ & $20 \%$ \\
Baoshan & $42 \%$ & $5 \%$ & $25 \%$ & $28 \%$ \\
Dali & $55 \%$ & $6 \%$ & $24 \%$ & $15 \%$ \\
Diqing & $70 \%$ & $4 \%$ & $19 \%$ & $7 \%$ \\
Nujiang & $67 \%$ & $5 \%$ & $17 \%$ & $11 \%$ \\
Total & $57.47 \%$ & $5.21 \%$ & $21.20 \%$ & $16.12 \%$ \\
\hline
\end{tabular}

According to household information, the primary access channel for loans was through family members, or rural credit cooperatives. Over $85 \%$ of respondents who had debts claimed that they accessed loans in these ways. Only $5 \%$ of these households claimed that they borrowed money from friends, and $4 \%$ stated that they borrowed from formal government banks.

\subsubsection{Access to insurance}

Access to insurance varied across the region. Ninety-eight percent of households had health insurance. Ninety-three percent and $91 \%$ of respondents from Lincang and Baoshan respectively, had life insurance. Around $80 \%$ of households in Nujiang had life insurance compared to only $41 \%$ of households in Diqing. Only $2 \%$ of households had insurance cover for damage to crops or other business problems.

Property insurance varied across the region. Half of surveyed households in Lincang had property insurance, but only $3 \%$ of households in Diqing. Livestock insurance was widely held. The highest percentage of households with insurance for their livestock was Nujiang (48\%) versus $21 \%$ in Dali (see Table 20). Almost all households have health and life insurance in the five prefectures since 2002, when a new rural cooperative medical insurance ${ }^{10}$ scheme was implemented in China.

\footnotetext{
${ }^{10}$ https://baike.baidu.com/item/新型农村合作医疗/4151870?fr=aladdin\&fromid=1616836\&fromtitle=新农合
} 
Table 20: Percent of surveyed of households covered by insurance

\begin{tabular}{lccccc}
\hline Insurance & Lincang & Baoshan & Dali & Diqing & Nujiang \\
\hline Property damage & $47 \%$ & $34 \%$ & $7 \%$ & $3 \%$ & $7 \%$ \\
Crop damage & $2 \%$ & $4 \%$ & $1 \%$ & $2 \%$ & $1 \%$ \\
Livestock death & $30 \%$ & $41 \%$ & $21 \%$ & $43 \%$ & $48 \%$ \\
Damage to business & $1 \%$ & $5 \%$ & $1 \%$ & $1 \%$ & $2 \%$ \\
Health & $98 \%$ & $99 \%$ & $99 \%$ & $98 \%$ & $99 \%$ \\
Life insurance & $93 \%$ & $91 \%$ & $59 \%$ & $41 \%$ & $79 \%$ \\
\hline
\end{tabular}

\subsubsection{Household involvement in community organizations}

Community organizations often mobilize resources and encourage sustainable resource management; therefore, they can influence climate change adaptation at the community level. Overall, $22 \%$ of households were involved in community organizations in 5 prefectures. Diqing had the highest rates of participation in community-based organizations (57\%). Baoshan had the lowest rates of participation with only $6 \%$ of respondents reporting involvement (see Figure 9).

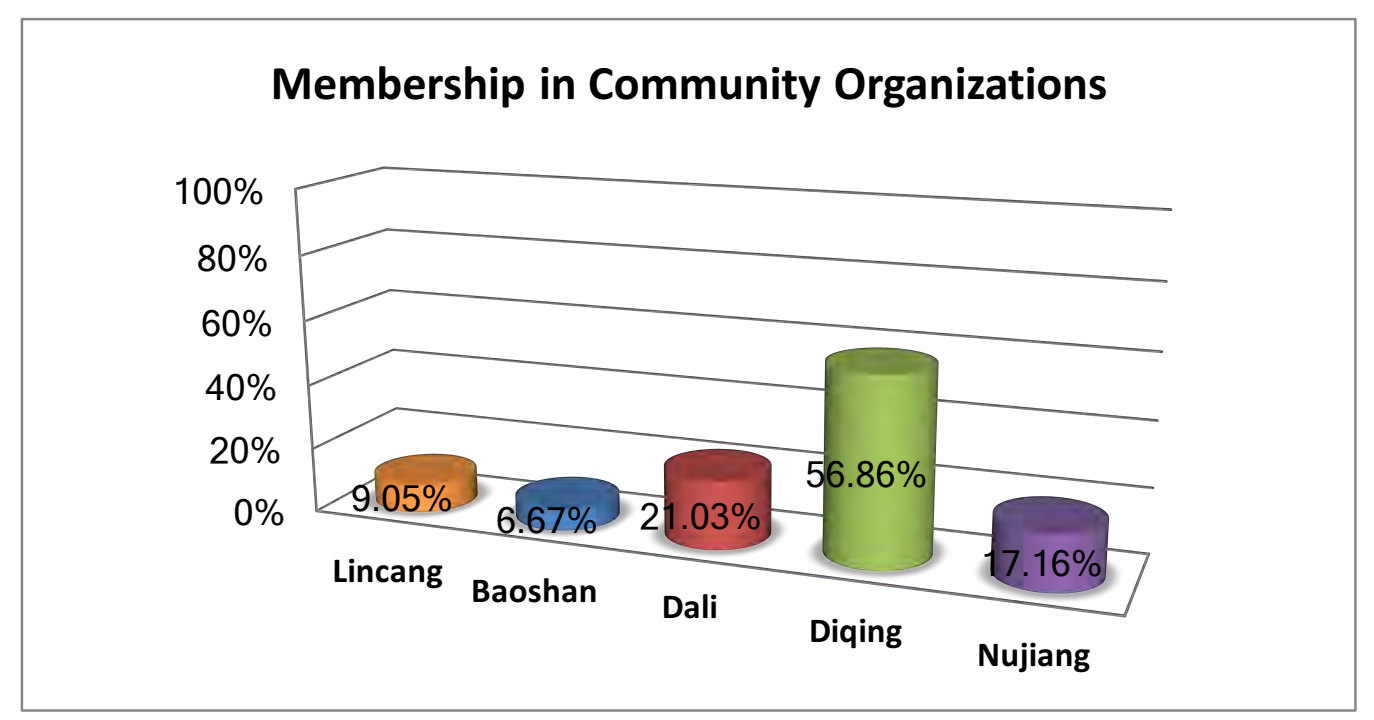

Figure 9: Percentage of total respondents that are members of community organizations

Participation in women's groups was highly diverse throughout the prefectures. Although these groups are referred to as 'women's groups' this designation is nominal, as in fact men are often members, and sometimes such groups are even led by men. Nonetheless, women were usually the majority members of women's organizations. The exception was Diqing where male participation was $25 \%$ higher than that of women. There were no women's groups in Baoshan (see Figure 10). 


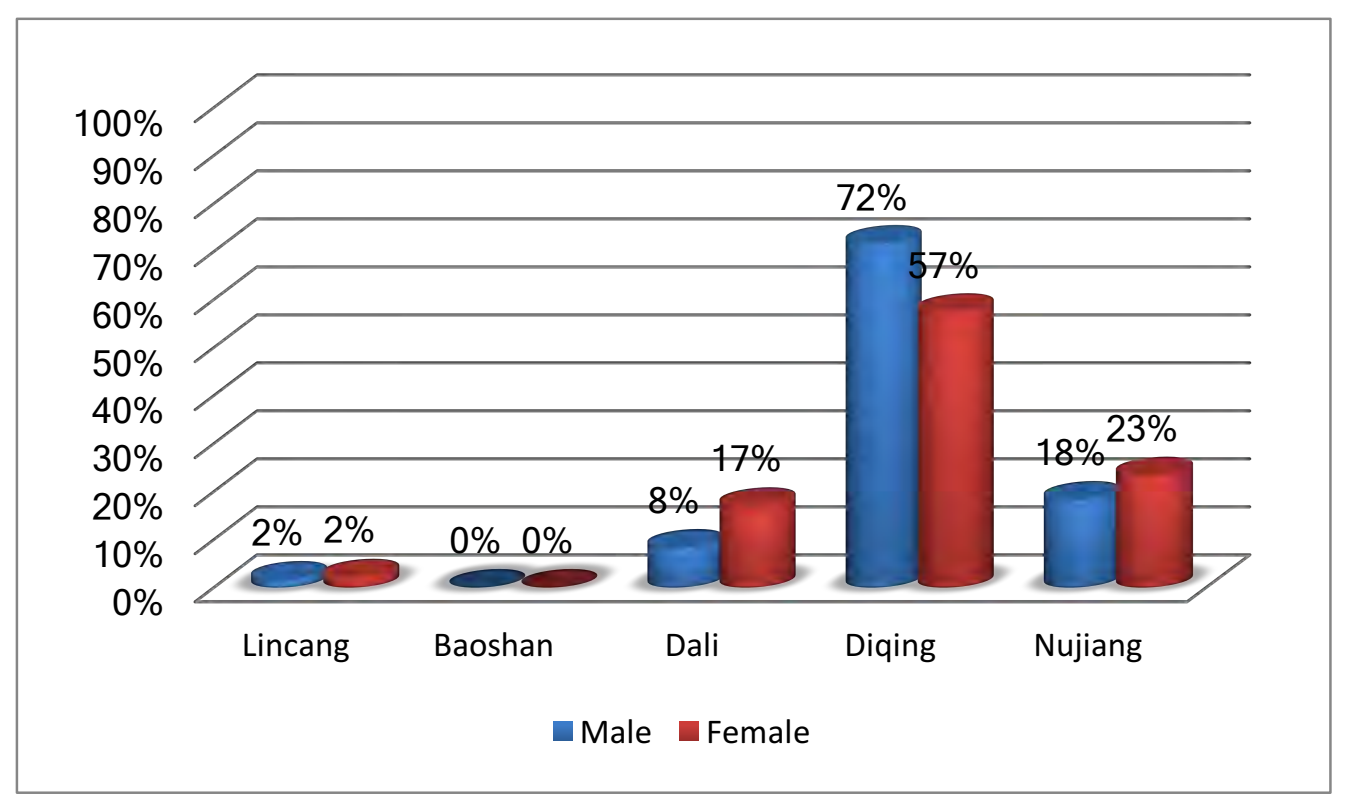

Figure 10: Membership in women's groups

\subsection{Water security}

\subsubsection{Access to water}

During the rainy season, $5 \%$ of respondents lacked sufficient piped water and had to spend approximately 25 minutes per day collecting water. During the dry season, 15\% of households lacked a sufficient supply of piped water. In Lincang, 16\% of households spent 49 minutes or more carrying water during the dry season (by foot, bicycle or motorbike). In Baoshan, $22 \%$ of households spent 36 minutes or more carrying water during the dry season. The time spent in water collection activities in Dali, Diqing and Nujiang was twice as long in the dry season than in the wet season. Baoshan and Lincang had the greatest seasonal variation in the need to collect water from elsewhere (see Table 21).

Table 21: Percentage of households needing to collect water from other areas, for five prefectures during the rainy or the dry season

\begin{tabular}{lrrrr}
\multicolumn{1}{c}{ Prefecture } & \multicolumn{2}{c}{ Rainy Season } & \multicolumn{2}{c}{ Dry Season } \\
& Percent & Time (minutes) & Percent & Time (minutes) \\
\hline Lincang & $2 \%$ & 30 & $16 \%$ & 49 \\
Baoshan & $5.4 \%$ & 30 & $22 \%$ & 36 \\
Dali & $2.5 \%$ & 19 & $5 \%$ & 35 \\
Diqing & $4 \%$ & 19 & $4 \%$ & 35 \\
Nujiang & $5 \%$ & 11 & $7 \%$ & 21 \\
Total/Average & 3.78 & 21.8 & 10.8 & 35.2 \\
\hline
\end{tabular}

\subsubsection{Water quality}

Water quality was correlated with water treatment, including boiling, precipitation, filtration and chemical treatment. For households who reported poor water quality, over $86 \%$ of households claimed that they often or always treated water before drinking, but only $74 \%$ of households treated their water if the head of the household believed that the drinking water was already 
safe. A quarter of respondents in Diqing claimed they had never treated their drinking water because they believed it was safe, whereas $85 \%$ of Baoshan and Dali respondents claimed they often or always treated their drinking water.

Perceptions of water quality varied between prefectures; $93 \%$ of households in Diqing and $80 \%$ of respondents in Lincang claimed that they had good or very good drinking water quality. $10 \%$ of respondents from Baoshan reported that they had poor or very poor water quality (see Table 22).

This survey found no correlation between water quality and personal health (t-test, $t=2.15, p>0.05$ ). Two factors are believed to be at work. First, the water in the villages is potable, and it is safe to drink water from wells or streams directly. Second, red tea is consumed frequently in these villages, the consumption of which requires the use of boiled water rather than un-boiled water. Local households are unaware that their water is being treated through the boiling process. However, it is proven elsewhere that the purification of drinking water leads to a decrease in the incidence of waterborne diseases that are linked to serious health problems (Pacific Institute, 2010).

Table 22: Percentage of households that treat their drinking water

\begin{tabular}{lccccc}
\hline Water treatment & Never & Rarely & Sometimes & Often & Always \\
\hline Lincang & $2 \%$ & $6 \%$ & $11 \%$ & $32 \%$ & $49 \%$ \\
Baoshan & $2 \%$ & $1 \%$ & $8 \%$ & $35 \%$ & $54 \%$ \\
Dali & $12 \%$ & $2 \%$ & $1 \%$ & $50 \%$ & $33 \%$ \\
Diqing & $25 \%$ & $2 \%$ & $11 \%$ & $41 \%$ & $20 \%$ \\
Nujiang & $10 \%$ & $11 \%$ & $13 \%$ & $41 \%$ & $25 \%$ \\
\hline
\end{tabular}

\subsubsection{Ability to purchase drinking water}

Drinking water is a necessity of life, but at some point in the year, households' normal local supply of freshwater may dry up. In such cases, it is a great advantage for households to be able to travel elsewhere to purchase drinking water. Often this may involve driving a vehicle to another location (a neighbour's land or a government water supply), filling containers with purchased water and driving back home. This requires considerable financial resources, which may be beyond the reach of some households. Significant variations were detected between households in their ability to engage in such an activity. We will refer to this as their 'water purchasing power', which varied between prefectures (Nujiang vs Lincang, Nujiang, $\mathrm{P}<0.01$ ). If households stated that they never or rarely purchased water without stating that they had 'no need to purchase water', then they were considered as 'unable to afford' water purchase. Ten percent of households in Lincang and Nujiang reported that they could not afford to purchase water. Thirteen percent of respondents in Dali and Diqing claimed that they could not afford the water, while $40 \%$ of respondents in Nujiang believed that it was unaffordable.

\subsection{Perceptions of climate change}

In recent years, climate change has risen to the forefront of public attention in Yunnan, because of associated frequent droughts. This negative impact of climate change has alarmed policy makers into increasing adaptation and mitigation through stricter control of deforestation. 
Perceptions of climate change varied greatly between genders and across locations. In total, over $80 \%$ of participants claimed that they had observed climate change in the last 10 years. (86\% of respondents reported observations of climate change in Lincang, based on their observations of erratic rainfall and high frequency of drought).

Respondents in Baoshan were most likely to report observing climate change (for both male and female-headed households, accounting for $95 \%$ and $90 \%$ of respondents respectively). Households in Nujiang had relatively low awareness of climate change; only $70 \%$ of male-headed households and $65 \%$ of female-headed households reported changes in the last 10 years.

Table 23: Percentage of households who had observed climate change

\begin{tabular}{lccc}
\hline Prefecture & Gender & Yes & No \\
\hline \multirow{2}{*}{ Lincang } & Male & $88.03 \%$ & $11.97 \%$ \\
& Female & $82.08 \%$ & $17.92 \%$ \\
\hline \multirow{2}{*}{ Baoshan } & Male & $94.33 \%$ & $5.67 \%$ \\
& Female & $89.68 \%$ & $10.32 \%$ \\
\hline \multirow{2}{*}{ Dali } & Male & $76.54 \%$ & $23.46 \%$ \\
& Female & $76.11 \%$ & $23.89 \%$ \\
\multirow{2}{*}{ Diqing } & Male & $79.26 \%$ & $20.74 \%$ \\
& Female & $84.04 \%$ & $15.96 \%$ \\
\hline \multirow{2}{*}{ Nujiang } & Male & $71.00 \%$ & $29.00 \%$ \\
& Female & $63.51 \%$ & $36.49 \%$ \\
\hline
\end{tabular}

Climate change was difficult to evaluate. The effects of climate change are multi-dimensional and can affect communities in direct or indirect ways. For instance, $30 \%$ of all households perceive that drought has been more frequent in the last 10 years, while $27 \%$ have also perceived erratic rainfall (see Figure 11). 


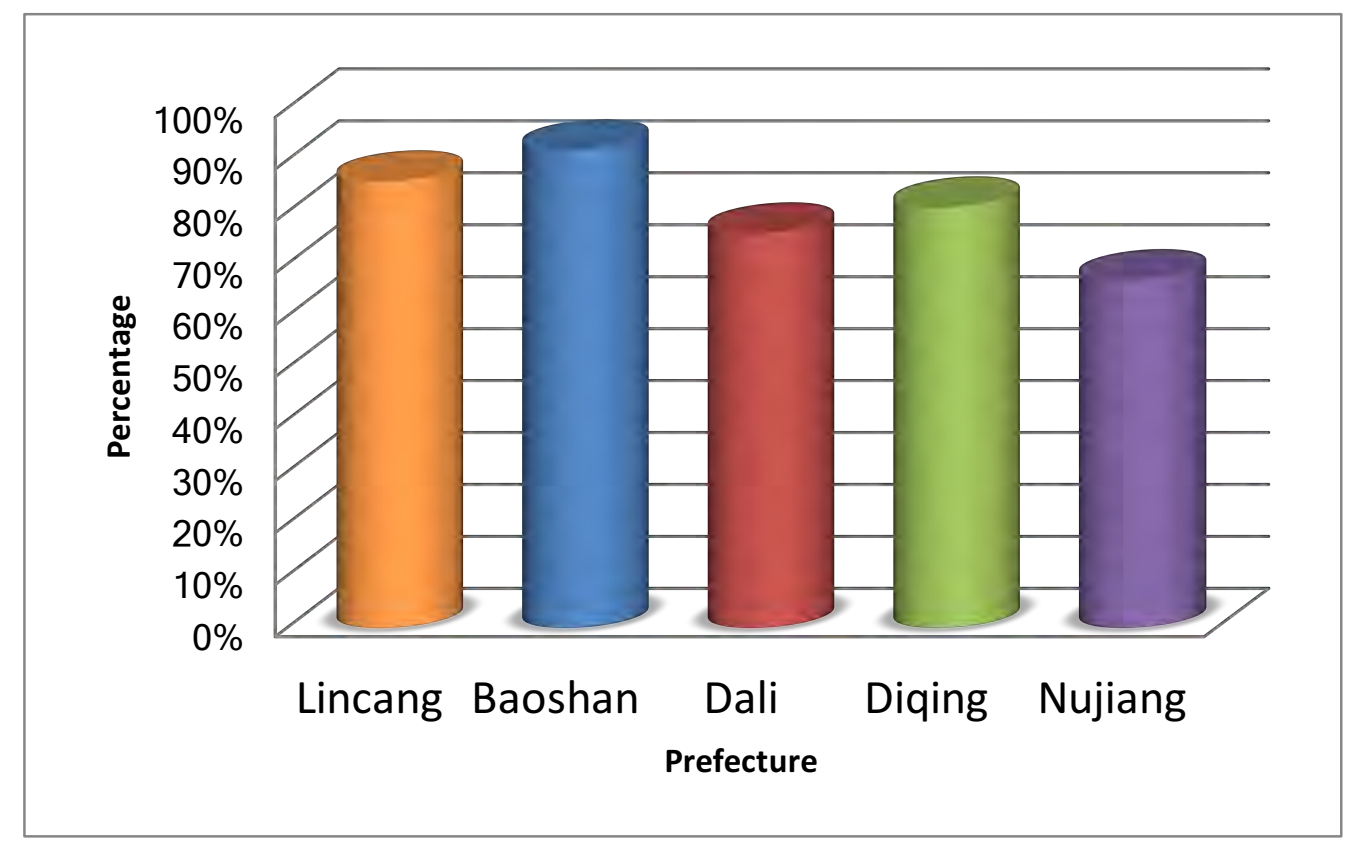

Figure 11: Percentage of total respondents that perceived climate change over the last 10 years

Over $80 \%$ of respondents claimed that summer temperatures have increased over the past 10 years. Geography (altitude and latitude) could play an important role in how households perceive temperature change. In Baoshan, Diqing, and Nujiang, more than half of respondents reported significantly warmer temperatures over the last 10 years. However, $70 \%$ of households in Dali reported no temperature change. Dali has abundant water resources and is about $2000 \mathrm{~m}$ above sea level on average, much higher than Lincang (about $1500 \mathrm{~m}$ in average). Precipitation changes were more commonly reported than changes in temperatures. Eighty-five percent of households reported changes in precipitation over the last 10 years. These changes largely consisted of delayed and irregular precipitation.

Lincang

Thirty percent of respondents in Lincang reported that in response to climate-related shocks, they introduced new types and varieties of crops. In addition, 10\% of households opted to keep new types of livestock. Twenty-eight percent of respondents reported that they would change their farming practices and $17 \%$ stated that they would look for off-farm activities.

\section{Baoshan}

Data from Baoshan showed significantly different perceptions of climate change ( $t$-test, $t=5.71$, $P \leq 0.01)$. Over half of all respondents indicated warmer temperatures during cold seasons; however, more male-headed households supported this claim. Twenty-six percent of respondents in Baoshan reported that they have introduced new crops and varieties in response to climate change, while $37 \%$ would adjust their farming techniques due to climate change.

\section{Dali}

In Dali, there was no significant difference in perceptions of climate change between male- and female-headed households ( $t$-test, $t=2.63, p \geqslant 0.05$ ). Over $70 \%$ of male and female participants believed that the climate had changed, and half of them supported the idea that that 
the hot season was getting hotter and the cold season was getting colder. It is also worth noting that over $90 \%$ reported that precipitation decreased over the past 10 years, especially in summer.

\section{Diqing}

In Diqing, $79 \%$ of all participants cited changes in precipitation. Forty-one percent of all respondents reported a precipitation delay. Half of all households stated that there was no observed decrease in rainy or snowy days.

\section{Nujiang}

In Nujiang, no gender differences were detected in changed perceptions of temperature and precipitation. Around $41 \%$ of all respondents cited a decrease in annual precipitation while around a quarter reported an increase in annual precipitation. One quarter mentioned that summer precipitation had decreased. Seventy-nine percent of male-headed households and $84 \%$ of female-headed households described changes in temperature.

\subsection{Vulnerability and Adaptive Capacity Assessment}

\subsubsection{Perception of shocks and impacts}

Climate-induced vulnerability can be manifested in natural, social or economic shocks that affect communities in several direct or indirect ways. The severity of shocks can be affected by numerous factors such as location, gender or economic status. In order to better understand the type and severity of shock events, all recorded events were categorized as standard values; from 1 (the least severe shock level) to 5 (the most severe shock level). The measure comes with three elements: 1) event that the households experience, 2) the severity of the event, 3) financial cost of mitigating the event.

Throughout the prefectures, family members who fell ill, livestock disease, drought (impact of lower than average precipitation in a single year), extended drought [impact of lower than average precipitation across multiple years, for example the drought of 2009 to 2012 in Yunnan, in which meteorological drought occurred in 90 monitoring stations in the province. More than 120 small and medium-sized rivers were cut off; and more than 400 small reservoirs and dam ponds dried up in 2012 (China Youth Daily, February 21, 2012)] ${ }^{11}$. Crop pests and strong winds were the most common type of shocks. However, shock frequency varied by location.

According our data analysis, external coping mechanisms to mitigate shocks and consequent damage were used in all prefectures. Generally, the first option for coping with shock was to seek help from family members, followed by help from friends and finally from the wider community. However, the use of external strategies such as seeking help from family members and friends varied with location and gender.

Lincang

In Lincang, illness among family members, livestock disease, drought, extended droughts, crop pests and strong winds were all cited as shocks experienced in the last 12 months. Overall, illness was ranked as the most severe event. All respondents ranked it as one of the top three most

${ }^{11}$ https://wenku.baidu.com/view/f1b69556c850ad02de804131.html 
severe shock events which incurred the highest costs due to damage. Male-headed households spent USD 1138.27 per household and female-headed households spent USD 797.61 on obtaining treatment for ill family members.

Male-headed house households may be more likely to use emergency medical services while female-headed households could be more likely to engage in preventive care.

Livestock disease was also considered a severe shock. Female-headed households spent USD 1126.98 mitigating against livestock disease, which was USD 460.81 more than male-headed households. Economic losses due to livestock disease were greater in female-headed households when compared to male-headed households. All households ranked extended drought and drought as serious causes of economic loss. However, male-headed households spent USD 187.46 more in mitigating against drought (see Table 24).

Table 24: Severity of shocks and damage in Lincang, by gender of the head of each household

\begin{tabular}{llclc}
\hline \multirow{2}{*}{ Lincang } & \multicolumn{2}{c}{ Male-headed HH } & \multicolumn{2}{c}{ Female-headed HH } \\
& Problems/Shocks & Severity/Damage* & Problems & Severity/Damage \\
\hline \multirow{2}{*}{ Severity of } & Family sickness & 4.56 & Livestock disease & 4.4 \\
shocks (top & Livestock disease & 4.21 & Drought & 4.11 \\
5) & Drought & 4.12 & Family sickness & 4.1 \\
& Strong winds & 4.1 & Extended drought & 4.07 \\
Damage or & Family sickness & 3.81 & Crop pest & 4 \\
economic & Livestock disease & 666.17 & Family sickness & 797.61 \\
loss caused & Drought & 517.26 & Extended drought & 433.09 \\
by shock (top & Extended drought & 470.21 & Drought & 329.80 \\
5) (USD) & Strong wind & 305.39 & Strong wind & 266.95 \\
\hline
\end{tabular}

(*Severity/damage: severity is grouped into 5 categories, ranging from 1 to 5 . The largest number, the high level of threats from that event. The unit for damage is dollar)

In Lincang, 33\% of male-headed households borrowed money from relatives to mitigate against damage caused by shocks, $30 \%$ encouraged family members to become migrant labourers, and around $24 \%$ of male-headed households themselves migrated as an entire household to other communities. Thirty-six percent of female-headed households in Lincang borrowed money from relatives, $23 \%$ migrated to other places, and $20 \%$ reduced the money spent on food consumption by the household.

\section{Baoshan}

In Baoshan, family sickness, strong wind, extended droughts, drought, and erratic rainfall were the top five most severe and damaging shocks. Family sickness, like that in Lincang, was the most severe shock for all respondents, costing between USD 936.5-971.41. Strong wind was also highly ranked as a shock affecting all households, although male-headed households incurred USD 171.06 more costs than their counterparts. Female-headed household ranked extended droughts as the second most severe shock, but male-headed households incurred USD 112.33 
more associated costs but ranked it lower in severity.

Although drought and extended droughts are very similar in their impact; drought was ranked lower in severity, but all households incurred higher damage costs, male-headed households incurred USD 76.50 and female-headed households incurred USD 89.64 higher losses to extended droughts than to drought.

In Baoshan, 29\% of male-headed households responded to losses by borrowing money from relatives or becoming migrant labourers. Twenty-six percent of female-headed households borrowed money or migrated. However, only $22 \%$ of male-headed households sought salaried positions as their third coping strategy, while $20 \%$ of female-headed households preferred to reduce the food consumption of adults in the household (see Table 25).

Table 25: Severity of shocks and damage in Baoshan, according to gender of the head of household

\begin{tabular}{llclc}
\hline \multirow{2}{*}{ Baoshan } & \multicolumn{2}{c}{ Male-headed households } & \multicolumn{2}{c}{ Female-headed households } \\
& Problems/Shocks & Severity/Damage & Problems & Severity/Damage \\
\hline \multirow{2}{*}{ Severity of } & Family sickness & 4.4 & Family sickness & 4.42 \\
shock (top 5) & Strong wind & 4.15 & Extended droughts & 3.92 \\
& Extended droughts & 3.84 & Strong wind & 3.83 \\
& Erratic rainfall & 3.71 & Erratic rainfall & 3.71 \\
Damage or & Family sickness & 971.41 & Family sickness & 3.5 \\
economic loss & Strong wind & 477.93 & Drought & 936.50 \\
caused by & Drought & 402.56 & Strong wind & 312.92 \\
shock (top 5) & Extended droughts & 326.00 & Extended droughts & 306.87 \\
(USD) & Erratic rainfall & 325.61 & Erratic rainfall & 213.67 \\
\hline
\end{tabular}

$\underline{\text { Dali }}$

Shock events in Dali differed from those experienced in Lincang and Baoshan. Debt, labour shortage and hail storms were only recorded in Dali. There was a higher discrepancy between genders in their experience of shocks than was seen in other prefectures. The most severe event for male-headed households was debt, which was valued at a staggering USD 4669.33 per household. Sickness of family members was also a significant shock for all households. Female-headed households incurred USD 680.92 higher costs and rated family illness as the most severe shock that they experienced. All households in Dali experienced livestock disease, but male-headed households spent USD 611.22 than female-headed households. Only female-headed households listed labour shortage as a shock. Most ranked labour shortage as of low severity, but it incurred an average economic loss of USD 740.73 per household. Only male-headed households listed hail as a shock, estimating that resulting damage cost an average of USD 458.73 per household.

Coping strategies in Dali were similar to those used by respondents in Baoshan. All households borrowed money as their first option for coping. Twice as many male-headed households as female-headed households borrowed from banks. Thirteen percent of female-headed 
households migrated. Seventeen percent of male-headed households would choose to restrict household food consumption (see Table 26).

Table 26: Severity of shocks and damage in Dali by gender of head of household

Unit: USD

\begin{tabular}{llclc}
\hline \multirow{2}{*}{ Dali } & \multicolumn{2}{c}{ Male-headed households } & \multicolumn{2}{c}{ Female-headed households } \\
& Problems/Shocks & Severity/Damage & Problems & Severity/Damage \\
\hline \multirow{3}{*}{ Severity of } & Debt & 4.75 & Family sickness & 4.07 \\
shock (top 5) & Family sickness & 4.11 & Livestock disease & 3.62 \\
& Livestock disease & 3.83 & Drought & 3.4 \\
& Drought & 3.72 & Labour shortage & 2.66 \\
& Hail & 3.63 & Crop Pest & 2.6 \\
\cline { 2 - 5 } Damage or & Debt & 4669.33 & Family sickness & 2366.3 \\
economic loss & Family sickness & 1685.38 & Labour shortage & 740.73 \\
caused by & Livestock disease & 1013.99 & Livestock disease & 402.77 \\
shock (top 5) & Drought & 526.11 & Drought & 284.12 \\
(USD) & Hail & 458.73 & Crop Pest & 101.58 \\
\hline
\end{tabular}

\section{Diqing}

Sickness of family members, livestock disease, landslide/erosion, crop pests, extended droughts, and droughts were significant shocks experienced in Diqing. Both male- and female-headed households reported similar experiences. Sickness of family members was the greatest problem. Although the severity value was similar, the loss reported by female-headed households was USD 1671.34 more than reported by male-headed households. The severity of landslides/erosion was ranked lower by men than women; however, male-headed households reported spending USD 338.38 more than female-headed households. Overall, male-headed households spent more on shock reduction, the exception being expenditure related to the illness of family members.

In Diqing, $19 \%$ of male-headed households responded to damage by restricting adult food consumption, $16 \%$ would reduce total household consumption, and $11 \%$ tried to sell farmland. There were similar figures for female-headed households (see Table 27). 
Table 27: Severity of shocks and associated damage in Diqing by gender of head of household

\begin{tabular}{llllc}
\multicolumn{1}{c}{ Diqing } & \multicolumn{2}{c}{ Male-headed HH } & \multicolumn{2}{c}{ Unit: USD } \\
\cline { 3 - 5 } & Problems/Shocks & Severity/Damage & Problems & Severity/Damage \\
\hline \multirow{2}{*}{ Severity of } & Family sickness & 4.09 & Family sickness & 4.07 \\
shock (top 5) & Livestock disease & 3.79 & Landslide/erosion & 3.81 \\
& Crop pest & 3.68 & Livestock disease & 3.58 \\
Damage or & Extended drought & 3.45 & Crop pest & 3.55 \\
economic loss & Extended droughts & 97.4 & Drought & 3.38 \\
\cline { 2 - 5 } caused by & Landslide/erosion & 774.16 & Livestock disease & 3273.62 \\
shock (top 5) & Livestock disease & 523.80 & Drought & 435.78 \\
(USD) & Drought & 307.91 & Crop pest & 378.30 \\
\hline
\end{tabular}

\section{Nujiang}

Nujiang has experienced many of the same shocks as the other prefectures, except for rodent impact (the impact of rodents on food resources, either affecting standing crops, or consuming stored food), which seems to be a local shock. Illness of family members was a serious shock for all households. However, the impact of rodents was the most significant shock for female-headed households, incurring USD 2331.34 of damage. Only female-headed households identified rodent impact as a shock. All other shock and damage did not differ with household head's gender.

In Nujiang, male- and female-headed households engaged in the same external coping strategies as in other areas, but they used various internal coping strategies. Generally, female-headed households restricted food consumption, while male-headed households encouraged family members to seek salaried employment (see Table 28).

Table 28: Severity of shocks and associated damage in Nujiang by gender of head of household

\begin{tabular}{|c|c|c|c|c|}
\hline & & & & Unit: USD \\
\hline \multirow{2}{*}{ Nujiang } & \multicolumn{2}{|c|}{ Male headed households } & \multicolumn{2}{|c|}{ Female headed households } \\
\hline & Problems/Shocks & Severity/Damage & Problems & Severity/Damage \\
\hline \multirow{5}{*}{$\begin{array}{l}\text { Severity of } \\
\text { shock (top 5) }\end{array}$} & Family sickness & 3.95 & Rodent impact & 4 \\
\hline & Livestock disease & 3.79 & Family sickness & 3.75 \\
\hline & Strong wind & 3.68 & Livestock disease & 3.48 \\
\hline & Erratic rainfall & 3.68 & Strong wind & 3.2 \\
\hline & Drought & 3.28 & Erratic rainfall & 3 \\
\hline Damage or & Family sickness & 1273.78 & Rodent impact & 2331.34 \\
\hline economic loss & Livestock disease & 624.87 & Family sickness & 1320.96 \\
\hline caused by & Strong wind & 226.05 & Livestock disease & 476.48 \\
\hline shock (top 5) & Drought & 221.72 & Strong wind & 186.03 \\
\hline (USD) & Extended droughts & 221.38 & Drought & 178.00 \\
\hline
\end{tabular}


For a holistic evaluation of vulnerability and household shocks, it is necessary to thoroughly investigate the channels through which households seek help. Through our PVA survey, the channels which the respondents use for seeking help were analysed. The same five channels were identified by all respondents, namely; family, friends, community members, local government and community organizations. However, there was variation in the both the preferred channels and actual access to help. Ninety percent of households in Nujiang would seek help from family while only $73 \%$ of households in Lincang would seek help from family to recover from shocks. Respondents in Diqing were the most likely to seek help from fellow community members (see Table 29).

Table 29: Whether respondents sought help from fellow members of their community

\begin{tabular}{lcr}
\hline Prefecture & Yes & No \\
\hline Lincang & $15 \%$ & $85 \%$ \\
Baoshan & $14 \%$ & $86 \%$ \\
Dali & $32 \%$ & $68 \%$ \\
Diqing & $43 \%$ & $57 \%$ \\
Nujiang & $26 \%$ & $74 \%$ \\
\hline
\end{tabular}

Diqing and Nujiang sought help from the government at similar rates ( $14 \%$ ) while only $1 \%$ of respondents from other prefectures did so. Diqing respondents were the most likely to seek help from community organizations (Table 30).

Table 30: Whether respondents sought help from community organizations

\begin{tabular}{lll}
\hline Prefecture & Yes & No \\
\hline Lincang & $7 \%$ & $93 \%$ \\
Baoshan & $3 \%$ & $97 \%$ \\
Dali & $4 \%$ & $96 \%$ \\
Diqing & $17 \%$ & $83 \%$ \\
Nujiang & $10 \%$ & $90 \%$ \\
\hline
\end{tabular}

Respondents from Lincang were most likely to adapt their agricultural techniques to meet the impact of climate change. The respondents from Lincang ceased planting certain crops, such as maize, introduced new crops and introduced new breeds of livestock (see Table 31).

Table 31: Changes to crops and livestock

\begin{tabular}{lcclccccc}
\multicolumn{2}{l}{ Stopped planting certain types of crops } & \multicolumn{2}{l}{ Introduced new crop types and varieties } & \multicolumn{2}{l}{ Introduced new breeds of livestock } \\
\hline Prefecture & Changed & Unchanged & Prefecture & Changed & Unchanged & Prefecture & Changed & Unchanged \\
\hline Lincang & $14 \%$ & $86 \%$ & Lincang & $29 \%$ & $71 \%$ & Lincang & $10 \%$ & $90 \%$ \\
Baoshan & $9 \%$ & $91 \%$ & Baoshan & $26 \%$ & $74 \%$ & Baoshan & $4 \%$ & $96 \%$ \\
Dali & $1 \%$ & $99 \%$ & Dali & $0 \%$ & $100 \%$ & Dali & $0 \%$ & $100 \%$ \\
Diqing & $3 \%$ & $97 \%$ & Diqing & $4 \%$ & $96 \%$ & Diqing & $1 \%$ & $99 \%$ \\
Nujiang & $4 \%$ & $96 \%$ & Nujiang & $10 \%$ & $90 \%$ & Nujiang & $8 \%$ & $92 \%$ \\
\hline
\end{tabular}




\subsubsection{LVI analysis}

As mentioned previously, the data collected in this study was analysed using the Livelihood Vulnerability Index (LVI); a measure of vulnerability. Based on the LVI index, household vulnerability was categorized into seven indicators: social demographic, livelihoods, health, social networks, food, water, natural disaster and climate variability. Each component was made up of several sub-indicators that were measured on separate scales (see Table 32).

For the social-demographic component, three sub-indicators were used. First, the dependency ratio refers to dependents in the household (members under the age of 15 and over the age of 64), divided by the number of productive members of the household, (ages 15 to 64). The second indicator was the percentage of household heads with no formal education; and finally, the average age of household head.

The livelihoods sector encompassed three sub-indicators: percentage of households with family members not working in their own community; percentage of households entirely dependent on agriculture as a source of income; and Average Agricultural Livelihood Diversification Index. Average Agricultural Livelihood Diversification Index (ALDI), refers to the types of agricultural practices, such as farming, fishing, etc. divided by one. The higher the ALDI value, the more vulnerable the household.

The health sector was represented by three indexes; percentage of households' health affected by natural disasters; affordability of treatment for serious illnesses or injury, and frequency of serious illnesses. 


\section{Table 32: LVI components}

\begin{tabular}{|c|c|c|c|c|c|c|c|c|}
\hline Major components & Sub-components & Lincang & Baoshan & Dali & Diqing & Nujiang & Max & Min \\
\hline \multirow[t]{2}{*}{ Social-demographic } & Dependency ratio & 0.49 & 0.66 & 0.54 & 0.42 & 0.37 & 1 & 0 \\
\hline & $\begin{array}{l}\% \text { of household heads who never } \\
\text { attended school }\end{array}$ & 12.21 & 6.13 & 5.91 & 8.88 & 26.78 & 100 & 0 \\
\hline \multirow[t]{2}{*}{ Livelihoods } & $\begin{array}{l}\% \text { of households with family members not } \\
\text { working in their own community }\end{array}$ & 25.17 & 28.77 & 17.11 & 16.81 & 12.69 & 100 & 0 \\
\hline & $\begin{array}{l}\% \text { of households entirely dependent on } \\
\text { agriculture for their income }\end{array}$ & 29 & 25 & 11 & 23 & 13 & 100 & 0 \\
\hline \multirow{3}{*}{ Social networks } & $\begin{array}{l}\text { Households' influence on local } \\
\text { community's decision-making }\end{array}$ & 2.21 & 2.78 & 2.76 & 3.23 & 2.91 & 5 & 1 \\
\hline & Access to credit & 3.27 & 3.46 & 3.49 & 3.54 & 3.36 & 5 & 1 \\
\hline & $\begin{array}{l}\% \text { of households involved in community } \\
\text { organizations }\end{array}$ & 8 & 10 & 22 & 90 & 28 & 100 & 0 \\
\hline
\end{tabular}




\begin{tabular}{|c|c|c|c|c|c|c|c|c|}
\hline Major components & Sub-components & Lincang & Baoshan & Dali & Diqing & Nujiang & Max & Min \\
\hline \multirow[t]{2}{*}{ Health } & $\%$ of households whose health was & 18 & 23 & 19 & 31 & 24 & 100 & 0 \\
\hline & $\begin{array}{l}\text { Affordability of treatment for serious } \\
\text { illness or injury }\end{array}$ & 3.54 & 3.8 & 4.55 & 4.78 & 4.09 & 6 & 1 \\
\hline \multirow[t]{3}{*}{ Food } & Crop diversity index & 0.17 & 0.25 & 0.36 & 0.31 & 0.27 & 1 & 0.16 \\
\hline & Food purchasing index & 2.48 & 2.54 & 3.05 & 4.25 & 2.6 & 5 & 1 \\
\hline & $\%$ of households that do not save seeds & 95 & 97 & 80 & 90 & 82 & 100 & 0 \\
\hline \multirow[t]{2}{*}{ Water } & Ability to afford frequent water purchases & 4.33 & 4.26 & 4.17 & 3.21 & 3.92 & 5 & 1 \\
\hline & Source of drinking water & 3.18 & 3.27 & 3.21 & 3.06 & 3.19 & 5 & 1 \\
\hline \multirow{3}{*}{$\begin{array}{l}\text { Natural disasters } \\
\text { and climate } \\
\text { variability }\end{array}$} & 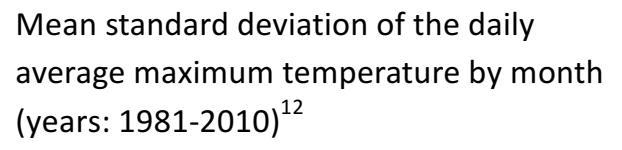 & 0.425 & 0.497 & 0.523 & 1.1 & 0.521 & 1.46 & 0.08 \\
\hline & $\begin{array}{l}\text { Mean standard deviation of the daily } \\
\text { average minimum temperature by month } \\
\text { (years: 1981-2010) }\end{array}$ & 0.71 & 0.809 & 0.956 & 0.467 & 0.707 & 1.63 & 0.09 \\
\hline & $\begin{array}{l}\text { Mean standard deviation of average } \\
\text { precipitation by month (years: 1981-2010) }\end{array}$ & 37.5 & 37.8 & 22.83 & 27.9 & 36.75 & 78 & 4.5 \\
\hline
\end{tabular}

12 Data source: Weather stations of research sites from the National Meteorological Information Centre (NMIC) of China 
Social networks were evaluated by using four indexes. First, the 'channels for seeking help' index, refers to the number of ways a household can seek help to cope with an emergency, divided by one. Values are assigned by evaluating the number of coping options a household has; the more options available, the lower the value of the index. Second, the influence of households on local community's decision-making for operational management and resource management, etc. Third, the number of options available to a household to access credit, and finally, the percentage of the households in the area who are involved in community organizations.

Access to and quality of food were measured using three indicators: Crop Diversity Index (CDI), which refers to the total number of crops planted by a household plus one and then divided by one. The percentage of households that do not save seeds is also used as an indicator along with the food purchasing index, which is based on expenditure on food just like Hahn (2009) initiated with the LVI index. The index is converted based on expenditure to indicate the vulnerability of households in each prefecture.

The water index is composed of the following three indicators: affordability of purchasing water, time spent on drinking water collection from the source, drinking water treatment and water quality.

For the last index, natural disasters and climate variability, four sub-indicators were used: probability of landslide occurrence, mean standard deviation of monthly average of average maximum daily temperature, mean standard deviation of monthly average of average minimum daily temperature, and the last mean standard deviation of monthly average precipitation.

Vulnerability in any one of the listed indicators may contribute to a household's ability to cope with shocks, but resilience is often most drastically affected when several pre-existing vulnerabilities are combine with sudden shocks.

A high rate of illiteracy (based on LVI analysis) coupled with demographics may lead to high vulnerability to climate change. Lincang had the smallest number of female-headed households (8\%). It was also calculated to be the least vulnerable prefecture.

However, based on livelihood indicators alone, Baoshan was calculated to be the most vulnerable and Nujiang the least vulnerable. Baoshan had the second largest number of households that depended entirely on agriculture as their source of income, (25\% of respondents), while Nujiang had only $13 \%$ of households that relied entirely on agriculture in this way. Dali had the highest value in the average agricultural livelihood diversification index (a sub-component of the livelihoods index), meaning that agricultural livelihoods were homogenous.

Households in Nujiang were the most likely to be severely affected by health-related shocks due to high frequency of serious illness and less affordable treatment. Based on reports of comparatively good health and affordability of treatment, households in Dali were least likely to be seriously affected by health issues.

Households in Lincang had weak social networks, while those in Diqing had the most robust social networks. Households in Lincang had less influence on their communities and found it more difficult to borrow money. 
Households in Baoshan were the most vulnerable when evaluating food indicators because $97 \%$ of them do not save seeds and spend much less than other prefectures in terms of food-purchasing index. Baoshan, Lincang and Nujiang had similar medium levels of the food-purchasing index. Dali and Diqing consumed much more food, as evaluated by the food-purchasing index.

Dali was the least vulnerable according to the livelihood sub-indicators, while Baoshan and Lincang were the most vulnerable. Based on the Average Agricultural Livelihood Diversification Index (based on the total number of agricultural activities conducted by each household), $95 \%$ of households were vulnerable in Lincang and 93\% in Baoshan.

Diqing households were most seriously affected by the affordability of purchasing water; although water in this area was reported to be of relatively good quality. There was a shortage of drinking water sources due to decreased precipitation and rising temperatures during the past two years. To optimize use of water resources, the Diqing government implemented strict regulations to curb industrial uses of water and imposed a quota for all use of underground water sources. ${ }^{13}$

Households in Nujiang were more likely to suffer the consequence of landslides, as their chance of having landslides was much higher than the rest places. Generally, households in Diqing were more likely to be affected by temperature changes and by precipitation.

Generally, Lincang and Baoshan were highly vulnerable in regard to livelihood and food indicators, while households in Nujiang were vulnerable to social demographic indicators. Nujiang province is made up primarily of minority peoples, of whom a high proportion are from the Lisu minority people group. Minority areas often receive less education and public services in China then the majority Han areas. These demographic factors could predispose this area to be more vulnerable to social demographic and climatic factors. Within Yunnan province, Nujiang sits at the second highest elevation, and shares a border with Myanmar. Nujiang has a high dependency rate, high illiteracy rates, low adaptive capacity and high exposure to risk.

Households in Baoshan were most vulnerable to elements of the food indicator while Diqing was most vulnerable with regard to the water indicator (see Table 33 \& Figure 12).

Table 33: LVI components (after standardization)

\begin{tabular}{|c|c|c|c|c|c|c|}
\hline $\begin{array}{l}\text { Major } \\
\text { components }\end{array}$ & Sub-components & Lincang & Baoshan & Dali & Diqing & Nujiang \\
\hline \multirow{4}{*}{ Social-demogr } & Dependency ratio & 0.49 & 0.66 & 0.54 & 0.42 & 0.37 \\
\hline & $\%$ of female-headed households & 0.08 & 0.09 & 0.16 & 0.3 & 0.24 \\
\hline & $\%$ of household heads who never attended school & 0.12 & 0.06 & 0.06 & 0.09 & 0.27 \\
\hline & Average age of household heads & 0.33 & 0.34 & 0.34 & 0.36 & 0.33 \\
\hline Livelihoods & $\begin{array}{l}\% \text { of households with family members not } \\
\text { working in their own community }\end{array}$ & 0.25 & 0.29 & 0.17 & 0.17 & 0.13 \\
\hline
\end{tabular}

${ }^{13}$ http://www.wcb.yn.gov.cn/arti?id=51163. 


\begin{tabular}{|c|c|c|c|c|c|c|}
\hline $\begin{array}{l}\text { Major } \\
\text { components }\end{array}$ & Sub-components & Lincang & Baoshan & Dali & Diqing & Nujiang \\
\hline & $\begin{array}{l}\% \text { of households entirely dependent on } \\
\text { agriculture for their income }\end{array}$ & 0.29 & 0.25 & 0.11 & 0.23 & 0.13 \\
\hline & $\begin{array}{l}\text { Average Agricultural Livelihood Diversification } \\
\text { Index }\end{array}$ & 0.95 & 0.928 & 0.8 & 0.88 & 0.892 \\
\hline & Means of seeking help index & 0.87 & 0.77 & 0.86 & 0.74 & 0.77 \\
\hline Social & $\begin{array}{l}\text { Households' influence on local community's } \\
\text { regulation }\end{array}$ & 0.7 & 0.56 & 0.56 & 0.44 & 0.52 \\
\hline \multirow[t]{3}{*}{ Networks } & Access to credit & 0.43 & 0.36 & 0.38 & 0.37 & 0.41 \\
\hline & $\begin{array}{l}\% \text { of households involved in community } \\
\text { organizations }\end{array}$ & 0.92 & 0.9 & 0.78 & 0.1 & 0.72 \\
\hline & $\begin{array}{l}\% \text { of households whose health was seriously } \\
\text { affected by natural disasters }\end{array}$ & 0.18 & 0.23 & 0.19 & 0.31 & 0.24 \\
\hline \multirow[t]{3}{*}{ Health } & $\begin{array}{l}\text { Affordability of treatment for serious illness or } \\
\text { injury }\end{array}$ & 0.49 & 0.44 & 0.29 & 0.24 & 0.38 \\
\hline & Frequency of serious illnesses & 0.13 & 0.12 & 0.11 & 0.11 & 0.2 \\
\hline & Crop Diversity Index & 0.01 & 0.1 & 0.23 & 0.17 & 0.13 \\
\hline \multirow[t]{3}{*}{ Food } & Food purchasing index & 0.63 & 0.61 & 0.48 & 0.18 & 0.6 \\
\hline & $\%$ of households that do not save seeds & 0.95 & 0.97 & 0.8 & 0.9 & 0.82 \\
\hline & Ability to afford frequent water purchases & 0.17 & 0.19 & 0.21 & 0.45 & 0.27 \\
\hline \multirow{4}{*}{ Water } & Source of drinking water & 0.45 & 0.43 & 0.44 & 0.48 & 0.45 \\
\hline & Treatments used for drinking & 0.19 & 0.15 & 0.27 & 0.43 & 0.34 \\
\hline & Perceptions of water quality & 0.27 & 0.33 & 0.29 & 0.24 & 0.26 \\
\hline & Probability of landslides & 0.25 & 0.4 & 0.42 & 0.42 & 0.61 \\
\hline \multirow{3}{*}{$\begin{array}{c}\text { Natural } \\
\text { disasters and } \\
\text { climate } \\
\text { variability }\end{array}$} & $\begin{array}{l}\text { Mean standard deviation of the daily average } \\
\text { maximum temperature by month }\end{array}$ & 0.25 & 0.3 & 0.32 & 0.74 & 0.32 \\
\hline & $\begin{array}{l}\text { Mean standard deviation of the daily average } \\
\text { minimum temperature by month }\end{array}$ & 0.4 & 0.47 & 0.56 & 0.25 & 0.4 \\
\hline & $\begin{array}{l}\text { Mean standard deviation of average precipitation } \\
\text { by month }\end{array}$ & 0.45 & 0.46 & 0.25 & 0.32 & 0.44 \\
\hline
\end{tabular}

Table 34: The value of LVI in the prefectures in this survey

\begin{tabular}{lccccc}
\hline \multicolumn{1}{c}{ Major components } & Lincang & Baoshan & Dali & Diqing & Nujiang \\
\hline Social-demographic & 0.255 & 0.288 & 0.275 & 0.293 & 0.303 \\
Livelihood & 0.497 & 0.489 & 0.360 & 0.427 & 0.384 \\
Social Networks & 0.730 & 0.648 & 0.645 & 0.413 & 0.605 \\
Health & 0.267 & 0.263 & 0.197 & 0.220 & 0.273 \\
Food & 0.530 & 0.560 & 0.503 & 0.417 & 0.517 \\
Water & 0.270 & 0.275 & 0.303 & 0.400 & 0.330 \\
Natural Disasters and Climate variability & 0.338 & 0.408 & 0.388 & 0.433 & 0.443 \\
\hline LVI & 0.412 & 0.419 & 0.381 & 0.372 & 0.408 \\
\hline
\end{tabular}




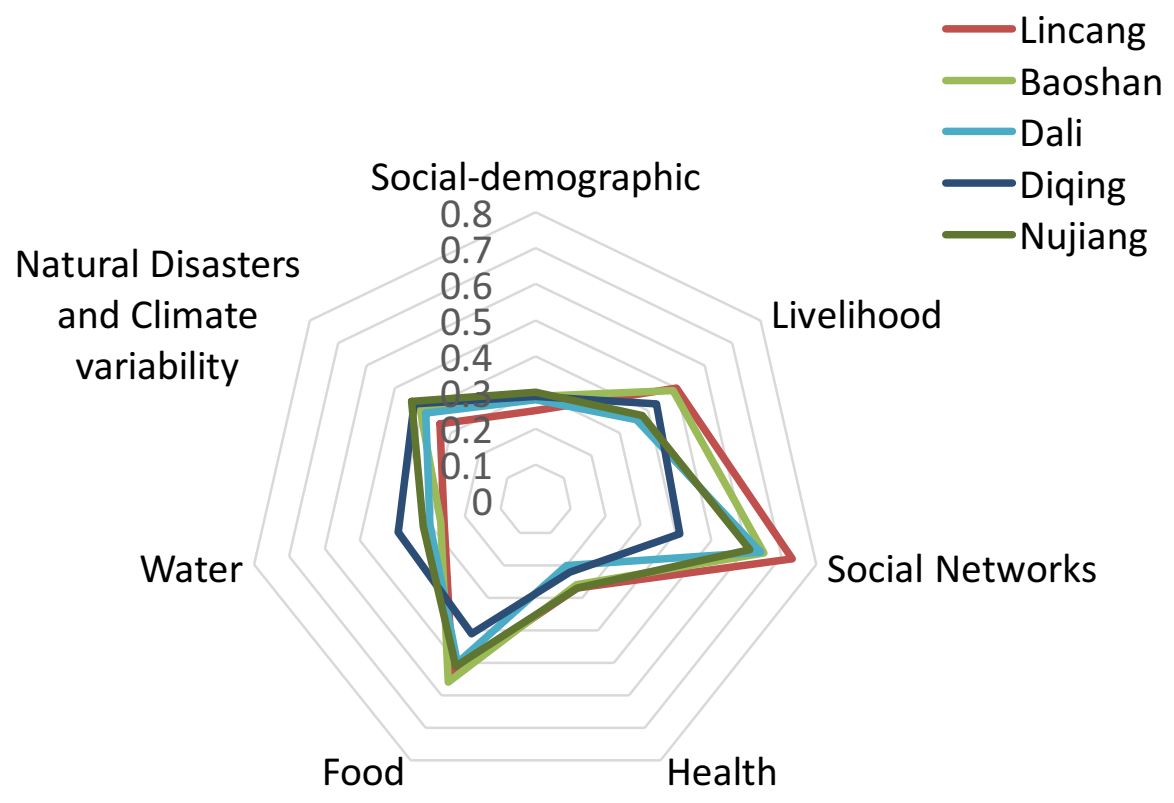

Figure 12: The value of LVI of surveyed prefectures: a graphical representation

\subsubsection{LVI-IPCC analysis}

The LVI-IPCC indexes varied across prefectures due to multiple factors. Diqing had the highest adaptive capacity, because it had the lowest dependency, the highest proportion of participation in community organizations and women's organizations; and the easiest access to credit. Lincang had the lowest adaptive capacity, due to the high proportion of households without any education; a high dependence on agricultural income; and the lowest participation of households in community organizations and women's organizations. Although Lincang had the highest amount of remittances, it nevertheless had the lowest average income.

Nujiang had the greatest exposure to environmental issues, due to its high variation in rainfall, high elevation and several major rivers (the Nu River, Lancang River, the Longjiang river and 183 tributaries). There has been serious land degradation, with high levels of debris flow in the rivers. Lincang's exposure to environmental issues was the lowest due to stable crustal movement in geography and temperature and low rates of debris flow.

Nujiang is the most sensitive area, due to its high disease incidence, low purchasing power, and the low levels of drinking water treatment. Dali has low sensitivity, due to its disease resistance, and high crop diversity (see Table 35 \& Figure 13). 
Table 35 The value of LVI-IPCC for the surveyed prefectures

\begin{tabular}{cccccc}
\hline Major components & Lincang & Baoshan & Dali & Diqing & Nujiang \\
\hline Adaptive capacity & 0.494 & 0.475 & 0.427 & 0.377 & 0.431 \\
Sensitivity & 0.356 & 0.366 & 0.334 & 0.346 & 0.373 \\
Exposure & 0.338 & 0.408 & 0.388 & 0.433 & 0.443 \\
LVI-IPCC & -0.056 & -0.025 & -0.013 & 0.019 & 0.004 \\
\hline
\end{tabular}

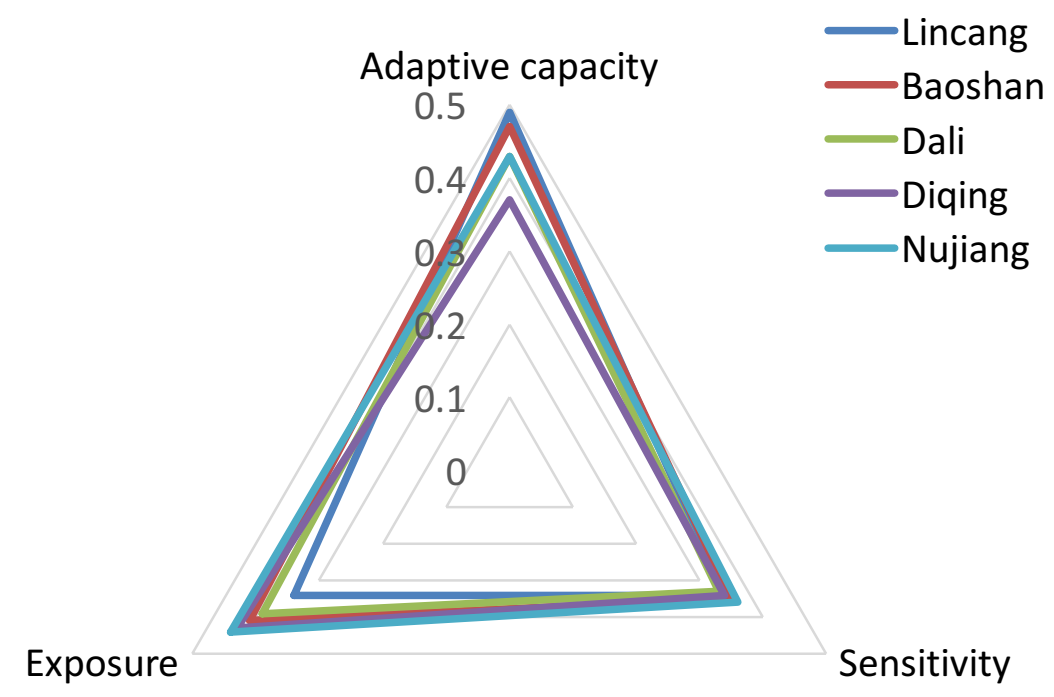

Figure 13: The value of LVI-IPCC of surveyed prefectures

\section{Discussion}

The LVI analysis used in this study relied on primary data gathered through our household survey. LVI analysis is meant to analyse micro-scale causal pathways of vulnerability. By using primary data this study gained a better understanding of how climate change is imbedded in a local context and avoided the speculation that can result from dependence on modeling climate change. Use of primary data can either establish a clear link in the form of ground truthing or in fact show problems with the climate modelling data. The analysis was used to derive measures of practical adaptations. These were compared with values from a literature review, leading us to feel confident that the LVI truly reflects the vulnerability of households to climate change. 


\subsection{Overall vulnerability to climate change and variations across the surveyed areas}

These 5 prefectures in Yunnan Province are already vulnerable to marginalization and climate change. The dependency ratio and illiteracy rate are very high, but migrant workers are paid low wages. Communities have few opportunities or access to loans, and little support from government. Therefore, households are often reliant on relatives and friends for help in times of difficulty (e.g. drought). They also have little or no chance to participate in or influence formulation and implementation of government policy. There are few farmer's associations or other self-organized groups at the village level. With rapid economic development and urbanization, the issues of adaptive capacity of households are not only due to environmental problems, but also relate to social structure, institutional arrangement, equity and their interactions. The sensitivity analysis showed that the proportion of rural households' health affected by natural disasters is relatively high. Moreover, while the frequency of major health issues is high, their ability to bear the economic burden of serious health issues is low. Therefore, sickness may push some households back into poverty. Households also listed disease as the second most serious risk that they currently face.

The crop diversity index is low, because few of the households save seeds. Many farmers are abandoning their traditional crops and shifting to cash crops. Although this strategy can bring in a higher cash income, it also makes them far more vulnerable and dependent on uncontrollable market forces and exposes them to new risks such as price fluctuations, seed dependence, water pollution and over-use of chemical fertilizers and pesticides.

The analysis of household risk exposure, showed that farmers mostly perceive changes in the environment, temperature and precipitation, but neither men nor women are aware of the risks of future climate change and related increase in the incidence and severity of natural disasters. As many households have limited education and technical skills, they may not be able to meet the increasing challenges of climate change and climate related disasters. For example, although households currently borrow money and water their crops during times of drought, (which cannot fundamentally solve their vulnerability), they do not appear to have any effective long-term response measures or strategies to meet future changes.

Although the LVI analysis showed little variation between prefectures, Lincang was found to be the most vulnerable prefecture. Respondents from Lincang reported that they experienced high food insecurity, had few social networks and little diversification in their livelihoods. Wa and Dai minority settlements are common throughout Lincang, which could be a contributing factor to vulnerability. However, none of Lincang's LVI indicators were drastically different from the other prefectures. This case is a good indication of how vulnerability is a combination of interrelated factors. Baoshan also had the highest vulnerability ranking, as its adaptability was low, and was highly sensitive to climate and exposure factors. Contributing factors were: a high dependency ratio, a heavy burden of labour, a high proportion of farmers whose main income source is from agriculture, and limited access to credit when facing the impact of climate change. 


\subsection{Food and social networks: the strongest indicators of vulnerability}

Overall, all indicator scores varied little across the five prefectures. The total LVI values per indicator showed greater variation. When the data was not split by prefecture, differences in social networks and factors relating to food were apparent.

\subsubsection{Food}

The sub-indicator that most affected overall vulnerability with regard to food was the percentage of households that do not save seeds for planting the next year's crops Since the late 1970s, hybrid seeds have been considered an important agricultural technology that increases yield, especially in rice production (Yuan, 1998). Almost all farmers in Yunnan use some variety of hybrid seeds since they are widely considered to be scientific and technologically advanced; resulting in higher productivity. Use of hybrid seeds has also been encouraged by national agricultural extension services. As Yunnan's microclimates change, there may be more opportunities to cultivate new crops and access new markets. Although there are many advantages to planting hybrid seeds, it also causes farmers to become dependent on seed manufacturers, the quality of whose seeds goes unregulated in China. The use of hybrid seeds has also decreased the use of traditional varieties and decreased overall agro-biodiversity, making certain varieties susceptible to disease, pests and changes in climate, potentially causing wide-scale crop failure. It seems that farmers understand the importance of producing their own seeds but consider this a technology of the past and so choose to buy hybrid seeds due to their obviously higher productivity (Dewi et al., 2015).

In addition to using hybrid seeds, households did not intentionally diversify their staple or cash crops. There has also been a shift away from traditional staple crops to cash crops. This represents a significant shift in production because farmers are now primarily producing grain for the market instead of for personal consumption (Gale, Tang, Bai \& Xu, 2005). In 1985, out of the total grain produced, $25 \%$ of was produced for sale and $75 \%$ was for self-consumption, either for human or animal consumption (Gale, Tang, Bai \& Xu, 2005). By 2003, sales of grain exceeded onfarm consumption (Gale, Tang, Bai \& Xu, 2005). In the context of LVI, this shift increases household vulnerability through a decrease in crop diversity; however, this particular subcomponent may be a reflection of market forces present in Yunnan province and the financial advantages of growing cash crops. As Yunnan's microclimates change there may be more opportunities to cultivate new crops and access new markets.

\subsubsection{Social networks}

Development in China often takes a top-down approach, under the direction of national, regional or provincial governments. Although, this is often beneficial in mobilizing disaster relief and emergency services, this approach may not produce long-standing, robust channels through which village-level communities can seek adaptation strategies to improve their long-term resilience. Based on our survey, it is clear that respondents more often access informal local channels of obtaining help in a time of household crisis. Most respondents stated that they would turn to their family members, friends or community members in a time of crisis. To 
participate in a top-down approach usually requires access to the local government and prominent community organizations that help create local policy. In all prefectures apart from Diqing, participation in local government and community organizations was extremely low. Most households felt that they had very little opportunity to influence local government policy. As a result, individual households have a very limited set of options if crisis arises. The lack of official and permanent channels for seeking help has created a particularly high level of systemic vulnerability across these five prefectures and across Yunnan Province more generally.

\subsection{Agricultural vulnerability to climate change and communities' adaptation}

\section{strategies}

Yunnan's agricultural production is vulnerable to climate change for several reasons. The large agricultural population increases pressures on natural resources, as well as having production areas that feature complex and deteriorating topography. In addition, the widespread use of hybrid seeds creates farmer dependency on seed manufacturers and decreases the use of traditional varieties that may be better able to adapt to changes in climate. Achieving sustainable agriculture during a period of climate change has been a challenge for most households in Yunnan, which is increasingly enhancing their vulnerability to food and livelihood indicators.

The similar adaptation strategies between the prefectures are notable and represents a general lack of adaptation options and resources throughout the entire region. The adaptation strategies are unlike those found in other areas because they lack innovation and necessary technology, but instead demonstrate only short-term awareness of vulnerability. In this case, many households may turn to short-term solutions because they do not recognize that climate change is likely to be a long-term problem. The year-to-year variability in temperature and precipitation are clearly identified by households throughout the five prefectures, but they may not have understood that they are part of a larger global problem of climate change. This may lead to adoption of solutions that are ineffective, temporary and costly, which may increase overall long-term vulnerability.

A vast majority of the strategies employed to mitigate household shocks are short-term strategies like borrowing money from friends and family, entering into wage labour, restricting adult consumption and migrating to other areas. Notably, only respondents in Diqing would sell farmland as a coping mechanism, and only respondents in Dali had access to banking institutions for loans. Dali is a newly developed area that relies heavily on tourism to support the local economy. Perhaps respondents from Dali can access formal financial institutions because most respondents in this area have off-farm employment. Off-farm employment could bring rural sections of the population into the city center and into close proximity to banks (Wang, Huang \& Rozelle, 2017; Li, Huang, Luo, \& Liu, 2013). Dali also had the highest rates of higher education and literacy, which would make it more feasible to join a formal institution such as a bank. Throughout all the prefectures, male-headed households were more likely to cite migration as a coping strategy, while female-headed households were more likely to restrict their food consumption. This could be because women are more responsible for child and elderly care which makes migration less appealing to them as an adaptive strategy (MPI, 2003). All these adaptive strategies are indicative of high vulnerability in social networks, which was seen as a provincial trend in the LVI-analysis. 


\section{Limitations of LVI}

Although our LVI analysis has led to important insights about vulnerability and adaptive capacity in Yunnan province, there are several drawbacks to this analysis. Climate change is indisputably a complex issue and by using a standardized form of analysis it oversimplifies the realities of vulnerability. Additionally, the LVI analysis was completed using an instrument that elicited respondents' perception of climate change and adaption strategies. Analysing respondents' perceptions may not necessarily provide a perfect result at the individual level, but can on aggregate levels provide a good impression of community level vulnerability. Therefore, data and analysis presented in this report should be interpreted in relation to current and historical contexts as well as other information sources. Furthermore, by using averages to quantify the LVI indicators, it can nullify differences within the subcomponents that may be significant. All of the LVI components are equally weighted, but some indicators may play a larger part in determining vulnerability (Hahn, Riederer \& Foster, 2008). The LVI analysis also does not accurately represent adaptive activities that the respondents currently undertake to reduce vulnerability. The LVI does not provide historical reason or context to why some groups or areas may be more vulnerable than others. It is also inadequate in capturing diversity of household-level interventions such as adjusting farming techniques, introducing new types of livestock, or changing consumption habits. This information is extremely important in understanding the local context and informing local policies and should be investigated through qualitative evidence. Moreover, the LVI analysis seems to be a stronger indicator for provincial-level vulnerabilities, rather than prefecture-level vulnerabilities, since there was little variation in the overall scores.

\section{Conclusion and recommendations}

This study has focused on how climate change could affect rural areas by conducting a vulnerability analysis. The specific information gleaned from this study can help inform general climate change policies in rural and mountainous areas in Yunnan Province and thus have the potential to create more resilient communities.

As a result of preexisting marginalization and climate change, these five prefectures in Yunnan Province are experiencing increasing vulnerabilities. Based on the data collected, climate change is significantly affecting mountain communities in Yunnan, while adaptation policies have not yet evolved to meet the challenges from the fast-changing context. The data collected in this initiative has clearly documented that communities' perceptions of changes in temperature, precipitation and fluctuating crop yields, are in accordance with scientific data on climate change. The lack of basic goods and services (i.e. clean water, accessible healthcare, durable housing) has compounded the impacts of climate change and has caused already poor, rural communities to become increasing vulnerable to climate change. These communities lack the resources necessary to find and implement long-term solutions and thus, unless there is future intervention, they are likely to continue to experience high vulnerability to climate change.

Our PVA survey showed that that some adaptation measures which could potentially be undertaken at a household or community-level (such as changing farming techniques, introduction of new plant varieties or livestock) are not necessarily being pursued by these communities. One possible explanation for this lack of innovation in adaptation could be that the Chinese national and regional governments highly regulate agricultural production even in 
mountain areas, which limits the ability of individual farmers to undertake their own adaptation measures. In order to encourage climate change adaptation, communities should have empowerment training in order to more effectively understand their individual role as agents of adaptation and how as farmers, they can become more resilient. By empowering local communities to critically assess their resources and the negative impacts of climate change, adaptation techniques will be more context-specific geographically and climatically, which will be more effective in the long-run. However, the PVA survey provides only perception of respondents, which only provides limited information. To conclusively diagnose vulnerabilities and the path to resistance, more research to identify deeper causes of vulnerability and understand the measures that could enhance the adaptive capacities should be undertaken jointly with rural communities.

Climate change can lead to severe impacts on the health of local communities, which is exacerbated by the under-developed health infrastructure in these rural areas. Rural communities are already vulnerable to health-related hazards due to poor quality and quantity of food and water. This further restricts the adaptive capacity of households coping with changing climatic conditions. In order to off-set new health risks, disaster-chains need to be studied to understand how hazards such as heat-waves, flooding and hurricanes will affect air quality, water quality, malnutrition and the spread of disease (Watts et al., 2015).

National and regional economics lie at the root of the vulnerability of poor rural households to climate change. These rural households have limited social networks, difficulty in accessing public services and public resources. They also have challenges in the areas of water access, energy provision and food security. Climate change could lead to an exacerbation of their current circumstances and further decrease their annual agricultural revenue. The development of China's national climate policy needs to be informed by solid research. Current theoretical analyses and pilot studies need to be validated by extensive research over wide and diverse areas. Currently rural households are unable to have input into government policy. They are only able to implement change at an individual or community level. Uninformed policies, in combination with a top-down approach can hinder any grassroot innovations and adaptive strategies that would be more effective at incorporating household level vulnerability and climate change into decision making and local action. To improve the current process, more stakeholders at the local level should be included in policy-making, so that a better process of holistic planning can shed light on new pathways to increase adaptive capacity in diverse geographical areas as well as developmental contexts. Local stakeholder involvement can lead to innovations that are more practical for rural households and better reach marginalized groups with short- and long-term adaptive strategies (Xu \& Grumbine, 2014; Agrawal, 2010).

One of the factors that most significantly affected the sensitivity, exposure and adaptive capacity of rural households was their access to information about agriculture and possible severe weather events. Overall vulnerability would decrease if rural mountainous communities had access to an agricultural information system to facilitate information flow about weather, agriculture technologies, and sustainable practices. Respondents to our survey perceive that the frequency of extreme weather has increased in the last 10 years. To prevent unnecessary economic loss and encourage adaptation to changing conditions, rural households should be using accurate information that can enable them to prepare for issues such as extreme weather events and crop diseases. These should be accessed through a convenient information delivery 
system. In the future, this could reduce the impact of climate change and decrease vulnerability. It will also encourage local innovation and ownership over climate change adaption, rather than relying solely on national policies.

Through community-level initiatives, it is possible to find solutions that could be community-specific, culturally-inclusive and long-lasting. In the future, it will be important to document the successes and failures of climate change adaptation in frontier landscapes like Yunnan Province. This knowledge can then be used in national policy-making. If future national policy is formed in a way that takes into account stakeholder views, needs and circumstances it would be a development that stands to benefit rural communities, not only in Yunnan province, but also throughout China. 


\section{References}

Adger WN. 2006. Vulnerability. Global Environmental Change - Human and Policy Dimensions 16: 268-281.

Agrawal A. 2010. Local institutions and adaptation to climate change. In the International Bank for Reconstruction and Development \& World Bank (Authors), Social dimensions of climate change: Equity and vulnerability in a warming world. Washington, DC: The Library of Congress. doi:10.1596/978-0-8213-7887-8.

Barton AP, Fullen MA, Mitchell DJ, Hocking TJ, Liu L, Bo, ... Xia. 2004. Effects of soil conservation measures on erosion rates and crop productivity on subtropical Ultisols in Yunnan Province, China. Agriculture, Ecosystems \& Environment 104: 343-357. doi:10.1016/j.agee.2004.01.034.

China Internet Information Centre. 2015. Yunnan province: China.org.cn. http://www.china.org.cn/e-xibu/2JI/3Jl/yunnan/yunnan-ban.htm .

Compilation Committee of the Second National Assessment Report on Climate Change. 2011. The second national assessment report on climate change. Beijing, China: Science Press.

Coulmas F, Conrad H, Schad-Seifert A, Vogt G. 2008. The demographic challenge: A handbook about Japan. Boston, MA: Brill.

Data Center of China Grain, 2015. http://www.stats.gov.cn/tjsj/zxfb/201512/t20151208 1286449.html. Accessed on May 9, 2017.

Dewi GAF, Argelis Gonzaléz V. 2015. GSDR 2015 Brief Conserving Traditional Seed Crops Diversity. United Nations Sustainable Development. https://sustainabledevelopment.un.org/content/documents/5739Conserving\%20traditional\%20 seed\%20crops\%20diversity.pdf. Accessed on Oct. 16, 2017.

Fazey I, Gamarra J, Fischer J, Reed M, Stringer L, Christie M. 2010. Adaptation strategies for reducing vulnerability to future environmental change. Frontiers in Ecology and the Environment 8(8): 414-422. http://dx.doi.org/10.1890/080215.

Gerlitz J, Banerjee S, Hoermann B, Hunzai K, Macchi M, Tuladhar S. 2014. Poverty and vulnerability assessment - A survey instrument for the Hindu Kush Himalayas. Kathmandu: ICIMOD. Hill Side Press (P.) Ltd., Kathmandu.

Gale F, Tang P, Bai XH, Xu HJ. 2005. Commercialization of Food Consumption in Rural China. Economic Research Report 8. United States Department of Agriculture.

Hahn M, Riederer A, Foster S. 2009. The livelihood vulnerability index: A pragmatic approach to assessing risks from climate variability and change-A case study in Mozambique. Global Environmental Change. doi:10.1016/j.gloenvcha.2008.11.002

Huang L, Chen AF, Zhu YH, Wang HL, He B. 2012. Trends of temperature extremes in summer and winter during 1971-2013 in China. Atmospheric and Oceanic Science Letters, 8(4): 220-225. http://dx.doi.org/10.3878/AOSL20150005.

ICIMOD (International Centre for Integrated Mountain Development). 2016. Hindu Kush Himalayan Region. Retrieved from http://www.icimod.org/?q=1137.

Intergovernmental Panel on Climate Change (IPCC). 2001a. Climate Change 2001: Impacts, Adaptation and Vulnerability, Summary for Policymakers, Working Group II: Impacts, Adaptation and Vulnerability, IPCC Third Assessment Report. http://www.ipcc.ch/ipccreports/tar/wg2/index.php?idp=5. Accessed on 23 June 2018. 
Intergovernmental Panel on Climate Change (IPCC). 2001b. Climate Change 2001: Synthesis Report, Contribution of Working Groups I, II and III, IPCC Third Assessment Report. Watson RT and the Core Writing Team (eds.), Cambridge University Press, Cambridge, United Kingdom.

Intergovernmental Panel on Climate Change (IPCC). 2001c. Climate Change 2001: Overview of Impacts, Adaptation, and Vulnerability to Climate Change. Working Group II: Impacts, Adaptation and Vulnerability, IPCC Third Assessment Report. http://www.ipcc.ch/ipccreports/tar/wg2/index.php?idp=54. Accessed on 23 June 2018.

Li Q, Huang J, Luo R, Liu C. 2013. China's labour transition and the future of China's rural wages and employment. China \& World Economy 21(3): 4-24.

Ma ZF, Liu J, Yang SQ. 2013. Climate change in southwest China during 196-2010: Impacts and adaptation. Advances in Climate Change Research, 4(4): 223-229. http://dx.doi.org/10.3724/SP.J.1248.2013.223.

Ma ZF, Liu J, Zhang SQ, Chen WX, Yang SQ. 2013. Observed climate changes in southwest China during 1961-2010. Advance Climate Change Research, 4 (1): 30-40. DOI: 10.3724/SP.J.1248.2013.00030.

Maharjan SK, Maharjan KL, Tiwari U, Sen NP. 2017. Participatory vulnerability assessment of climate vulnerabilities and impacts in Madi Valley of Chitwan district, Nepal. Cogent Food \& Agriculture 3: 1310078. http://dx.doi.org/10.1080/23311932.2017.1310078.

Nadin R, Opitz-Stapleton S, Xu Y. 2016. Editors. Climate Risk and Resilience in China. Routledge. Nordpil H. 2012. Himalaya Climate Change Adaptation Programme: Multidimensional poverty index (MPI) for the countries in the Hindu Kush Himalaya region. Retrieved from http://www.grida.no/graphicslib/detail/multidimensional-poverty-index-mpi-for-the-countries-in -the-hindu-kush-himalaya-region f192.

R Core Team. 2014. R: A language and environment for statistical computing. R Foundation for Statistical Computing, Vienna, Austria. Retrieved from http://www.R-project.org/.

Statistical Bureau of Yunnan Province (SBYP). 2016. Yunnan statistical yearbook (Vol. 32). China Statistics Press.

UNICEF. 2013. What Census Data Can Tell Us About Children in China Facts and Figures 2013. Retrieved from http://www.unicef.cn/en/uploadfile/2013/1216/20131216111141945.pdf.

Wang XB, Huang J, Rozelle S. 2017. Off-farm employment and agricultural specialization in China. China Economic Review 42: 155-165. http://dx.doi.org/10.1016/j.chieco.2016.09.004.

Watts N, Adger WN, Agnolucci P, Blackstock J, Byass P, Cai W, Chaytor S, Colbourn T, Collins M, Cooper A, Cox PM, Depledge J, Drummond P, Ekins P, Galaz V, Grace D, Graham H, Grubb M, Haines A, Hamilton I, Hunter A, Jiang X, Li M6, Kelman I, Liang L, Lott M, Lowe R, Luo Y, Mace G16, Maslin M, Nilsson M, Oreszczyn T, Pye S, Quinn T, Svensdotter M, Venevsky S, Warner K, Xu B, Yang J, Yin Y, Yu C, Zhang Q, Gong P, Montgomery H, Costello A. 2015. Health and climate change: policy responses to protect public health. Lancet 386(10006): 1861-1914. doi: 10.1016/S0140-6736(15)60854-6.

Xiao ZQ, Zhou GH, Quan WT. 2009. Distributive pattern of malignant invasive species, eupatorium adenophorum in Yunnan. Journal of Natural Disasters (in Chinese), 18(5): 82-87.

Xu J, Grumbine RE. 2014. Integrating local hybrid knowledge and state support for climate change adaptation in the Asian Highlands. Climate Change 124(1): 93-104. 
http://dx.doi.org/10.1007/s10584-014-1090-7.

Yuan LP. 1998. Hybrid rice development and use: Innovative approach and challenges. IRC Newsletter 47: 7-14.

Zomer R, Xu J, Wang M, Trabucco A, Li Z. 2015. Projected impact of climate change on the effectiveness of the existing protected area network for biodiversity conservation within Yunnan Province, China. Biological Conservation 184: 335-345. Retrieved from https://www.researchgate.net/publication/272976053 Projected_impact of climate change o n_the_effectiveness_of_the_existing_protected_area_network_for_biodiversity_conservation_w ithin_Yunnan_Province_China 


\section{Working Paper Series}

2017

268. Tree diversity and carbon stock in various land cover systems of Jayapura, Jayawijaya and Merauke Districts, Papua Province. http://dx.doi.org/10.5716/WP17359.PDF

269. Modelling tree production based on farmers' knowledge: case for kapok (Ceiba pentandra) and candlenut (Aleurites mollucana) under various agroforestry scenarios. http://dx.doi.org/10.5716/WP17361.PDF

270. The impact of land cover and climate change on present and future watershed conditions. Case study: Tugasan, Alanib and Kulasihan Sub-watershed of Manupali Watershed, Lantapan, Bukidnon, Philippines. http://dx.doi.org/10.5716/WP17362.PDF

271. Tree diversity and above-ground carbon stock estimation in various land use systems in Banjarnegara, Banyumas and Purbalingga, Central Java. http://dx.doi.org/10.5716/WP17363.PDF

272. Agroforestry and Forestry in Sulawesi series: Landscape Management Strategies in Sulawesi: Review of Intervention Options. http://dx.doi.org/10.5716/WP17364.PDF

273. Household food security and nutritional status of women and children in Buol Regency, Central Sulawesi, Indonesia. http://dx.doi.org/10.5716/WP17365.PDF

274. Palm oil expansion in tropical forest margins or sustainability of production? Focal issues of regulations and private standards. http://dx.doi.org/10.5716/WP17366.PDF

\section{8}

275. Decision analysis methods guide: Agricultural policy for nutrition http://dx.doi.org/10.5716/WP18001.PDF

276. Supporting human nutrition in Africa through the integration of new and orphan crops into food systems: Placing the work of the African Orphan Crops Consortium in context. http://dx.doi.org/10.5716/WP18003.PDF

277. Seri Pembangunan Ekonomi Pedesaan Indonesia. Pilihan Manajemen Budidaya Kacang Tanah sebagai Upaya untuk Memperbaiki Penghidupan Masyarakat Haharu. http://dx.doi.org/10.5716/WP18004.PDF

278. Estudio de línea de base CCAFS a nivel de hogar en Nicaragua y Costa Rica Fase de diagnóstico del estudio: “Contribución de la diversidad arbórea a los medios de vida para la adaptación y la mitigación al cambio climático. http://dx.doi.org/10.5716/WP18005.PDF

279. Understanding tree cover transition, drivers and stakeholder perspectives for effective landscape governance. A case study in $\mathrm{Na}$ Nhan commune, Dien Bien province, Vietnam. http://dx.doi.org/10.5716/WP18006.PDF

280. Agroforestería y manejo de suelos para la producción de maíz y frijol en laderas. http://dx.doi.org/10.5716/WP18007.PDF

281. Probabilistic decision modelling to determine impacts on natural resource management and livelihood resilience in Marsabit County, Kenya. http://dx.doi.org/10.5716/WP18008.PDF

282. Shifting discourse, shifting power: how is climate change mitigation and justice negotiated in Indonesia? http://dx.doi.org/10.5716/WP18009.PDF

283. Result of Land Use Planning and Land Administration (LULA) implementation in South Sumatra, East Kalimantan, Central Java and Papua. http://dx.doi.org/10.5716/WP18010.PDF

284. Farmers' preferences for training topics and dissemination of agroforestry information in Indonesia. http://dx.doi.org/10.5716/WP18015.PDF

285. CSA-Diagnostic (CSA-Dx): A primer for investigating the 'climate-smartness' of ag technologies. http://dx.doi.org/10.5716/WP18020.PDF 
The World Agroforestry Centre is a centre of scientific excellence that harnesses the benefits of trees for people and the environment. Leveraging the world's largest repository of agroforestry science and information, it develops knowledge practices for farmers' fields through to the global sphere to ensure food security and environmental stability.

The Centre's vision is an equitable world where all people have viable livelihoods supported by healthy and productive landscapes. Its mission is to harness the multiple benefits trees provide for agriculture, livelihoods, resilience and the future of our planet, from farmers' fields through to continental scales.

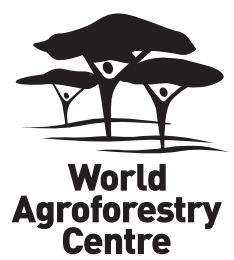

United Nations Avenue, Gigiri • PO Box 30677 • Nairobi, 00100 • Kenya Telephone: +254207224000 or via USA +16508336645 Fax: +254207224001 or via USA +1 6508336646 Email: worldagroforestry@cgiar.org•www.worldagroforestry.org 